\title{
TMI-2 LESSONS LEARNED TASK FORCE STATUS REPORT AND SHORT-TERM RECOMMENDATIONS
}

\section{MASTER}

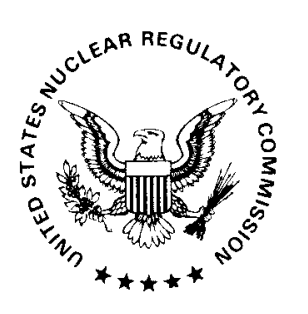

\author{
Office of Nuclear Reactor Regulation \\ U. S. Nuclear Regulatory Commission
}




\title{
Available from \\ U.S. Nuclear Regulatory Commission Washington, D.C. 20555
}

\author{
Available from \\ National Technical Information Service \\ Springfield, Virginia 22161
}




\section{DISCLAIMER}

This report was prepared as an account of work sponsored by an agency of the United States Government. Neither the United States Government nor any agency Thereof, nor any of their employees, makes any warranty, express or implied, or assumes any legal liability or responsibility for the accuracy, completeness, or usefulness of any information, apparatus, product, or process disclosed, or represents that its use would not infringe privately owned rights. Reference herein to any specific commercial product, process, or service by trade name, trademark, manufacturer, or otherwise does not necessarily constitute or imply its endorsement, recommendation, or favoring by the United States Government or any agency thereof. The views and opinions of authors expressed herein do not necessarily state or reflect those of the United States Government or any agency thereof. 


\section{DISCLAIMER}

Portions of this document may be illegible in electronic image products. Images are produced from the best available original document. 
NUREG-0578

\section{TMI-2 LESSONS LEARNED TASK FORCE STATUS REPORT AND SHORT-TERM RECOMMENDATIONS}

Manuscript Completed: July 1979

Date Published: July 1979

Office of Nuclear Reactor Regulation

U. S. Nuclear Regulatory Commission

Washington, D.C. 20555 
0 


\section{ABSTRACT}

Review of the Three Mile Island accident by the TMI-2 Lessons Learned Task Force has disclosed a number of actions in the areas of design and analysis and plant operations that the Task Force recommends be required in the short term to provide substantial additional protection which is required for the public health and safety. All nuclear power plants in operation or in various stages of construction or licensing action are affected to varying degrees by the specific recommendations. The Task Force is continuing work in areas of general safety criteria, systems design requirements, nuclear power plant operations, and nuclear power plant licensing. 
0

○ 


\section{TABLE OF CONTENTS}

$\underline{\text { Page }}$

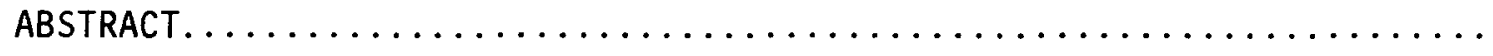

MEMBERS OF LESSONS LEARNED TASK FORCE.................... vii

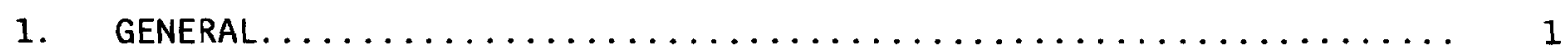

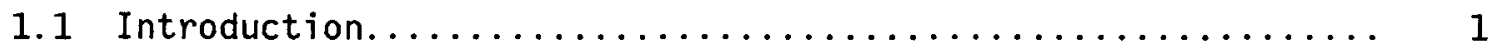

1.2 Task Force Operation and Coordination.................. 2

1.3 Implementation of Short-Term Licensing Requirements......... 4

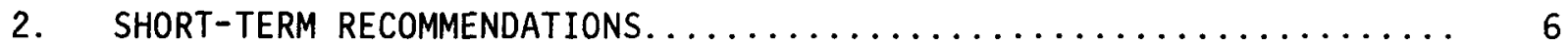

2.1 Design and Analysis.............................. 6

2.1.1 Emergency Power Supply Requirements for the Pressurizer Heaters, Power-Operated Relief and Block Valves, and Pressurizer Level Indicators in PWRs.............

2.1.2 Performance Testing for BWR and PWR Relief and Safety

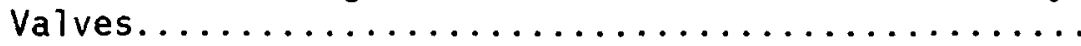

2.1.3 Information to Aid Operators in Accident Diagnosis and

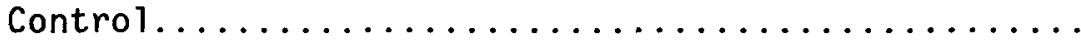

2.1.4 Containment Isolation Provisions for PWRs and BWRs....

2.1.5 Post-Accident Hydrogen Control Systems for PWR and

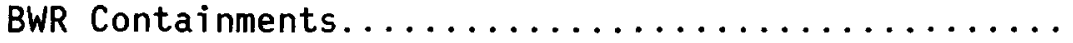

2.1.6 Post-Accident Control of Radiation in Systems Outside

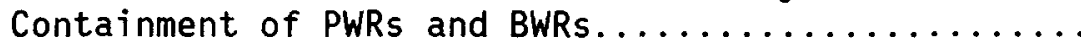

2.1.7 Improved Auxiliary Feedwater System Reliability for

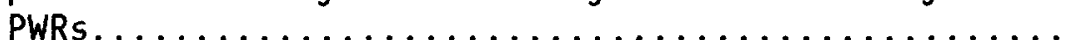

2.1.8 Instrumentation to Follow the Course of an Accident...

2.1.9 Analysis of Design and Off-Normal Transients and

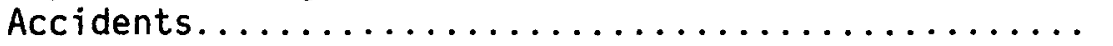

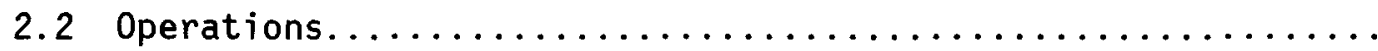

2.2.1 Improved Reactor Operations Command Function.........

2.2.2 Improved In-Plant Emergency Procedures and

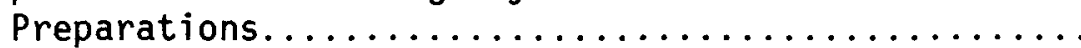

2.2.3 Revised Limiting Conditions for Operation of Nuclear Power Plants Based Upon Safety System Availability..

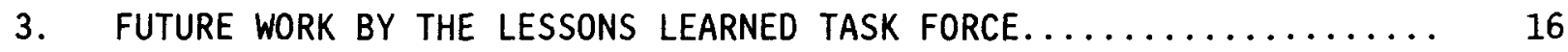

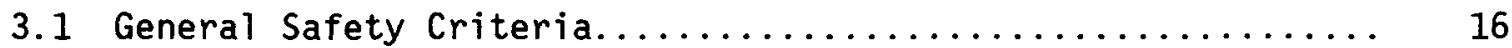

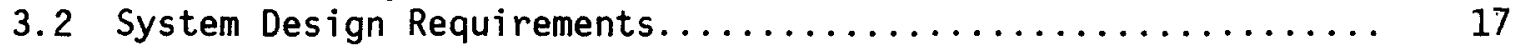

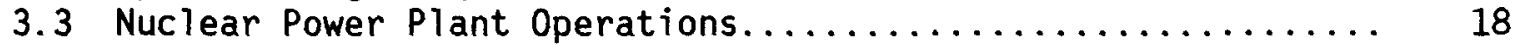

3.4 Nuclear Power Plant Licensing..................... 19 
TABLE OF CONTENTS (Continued)

Page

APPENDIX A NRR LESSONS LEARNED TASK FORCE SHORT-TERM RECOMMENDATIONS

2.1.1 Emergency Power Supply Requirements for the Pressurizer Heaters, Power-Operated Relief Valves and Block Valves and Pressurizer

Level Indicators in PWRs........................ A $\mathrm{A}-1$

2.1.2 Performance Testing for BWR and PWR Relief and Safety Valves................................ A-6

2.1.3. a Direct Indication of Power-Operated Relief Valve and Safety Valve Position for PWRs and BWRs................... A-9

2.1.3.b Instrumentation for Detection of Inadequate Core Cooling in PWRs and BWRs.................................

2.1.4 Diverse and More Selective Containment Isolation Provisions for PWRs and BWRs............................... A-13

2.1.5.a Dedicated Penetrations for External Recombiners or Post-Accident Purge Systems............................ A-16

2.1.5.b Inerting BWR Containments......................... A-19

2.1.5.c Capability to Install Hydrogen Recombiner at Each Light Water Nuclear Power Plant............................. A-21

2.1.6.a Integrity of Systems Outside Containment Likely to Contain Radioactive Materials (Engineered Safety Systems and Auxiliary Systems) For PWRs and BWRs................A-26

2.1.6.b Design Review of Plant Shielding of Spaces for Post-Accident Operations............................. A-28

2.1.7.a Automatic Initiation of the Auxiliary Feedwater System for PWRs. A-30

2.1.7.b Auxiliary Feedwater Flow Indication to Steam Generators for PWRs.................................

2.1.8. a Improved Post-Accident Sampling Capability............... A-34

2.1.8.b Increased Range of Radiation Monitors.................. A-36

2.1.8. C Improved In-Plant Iodine Instrumentation................. A-41

2. 1.9

2.2.1.a Analysis of Design and Off-Normal Transients and Accidents..... A-42 Shift Supervisor's Responsibilities.................... A-46

2.2.1.b

Shift Technical Advisor........................... A-49

2.2.1.c Shift and Relief Turnover Procedures................. A-52

2.2.2. a Control Room Access............................. A-55

2.2.2.b Onsite Technical Support Center..................... A-57

2.2.2.c Onsite Operational Support Center..................... A-59

2.2.3 Revised Limiting Conditions for Operation of Nuclear Power

Plants Based Upon Safety System Availability............. A-60

APPENDIX B IMPLEMENTATION OF SHORT-TERM RECOMMENDATIONS 
MEMBERS OF NRR LESSONS LEARNED TASK FORCE

\begin{tabular}{|c|c|c|}
\hline Roger Mattson & - & Division of Systems Safety \\
\hline Robert Tedesco & - & Reactor Safety \\
\hline Warren Minners & - & Division of Systems Safety \\
\hline Richard Ireland & - & Reactor Safety \\
\hline Charles Long & - & Plant Systems \\
\hline Tom Telford & - & Division of Operating Reactors \\
\hline John 01 shinski & - & Reactor Systems Branch \\
\hline Jose Calvo & - & Power Systems Branch \\
\hline John Voglewede & - & Core Performance Branch \\
\hline William Milstead & - & Containment Systems Branch \\
\hline Phillip Stoddart & - & Effluent Treatment Systems Branch \\
\hline Harry Krug & - & Radiological Assessment Branch \\
\hline Gary Holahan & - & Analys is Branch \\
\hline Leo Beltracchi & - & Instrumentation and Control Systems Branch \\
\hline Lake Barrett & - & Environmental Evaluation Branch \\
\hline Jerry Holman & - & Operator Licensing Branch \\
\hline Harley Silver & - & LWR Project Management Branch \\
\hline James Conran & - & Standardization Branch \\
\hline Larry Chandler & - & Office of Executive Legal Director \\
\hline James Milhoan & - & Office of Standards Development \\
\hline Robert Cudlin & - & Office of Nuclear Regulatory Research \\
\hline Terry Harpster & - & Office of Inspection and Enforcement \\
\hline
\end{tabular}




\section{TMI-2 LESSONS LEARNED TASK FORCE \\ STATUS REPORT AND \\ SHORT-TERM RECOMMENDATIONS}

\section{GENERAL}

\subsection{Introduction}

On March 28, 1979, the Three Mile Island Unit 2 (TMI-2) nuclear power plant experienced a loss of feedwater transient that led to a series of events culminating in a partially mitigated loss-of-coolant accident (LOCA) with significant core damage. On the basis of information available at this time, it is understood that the sequence of events that led to core damage involved equipment malfunctions, design deficiencies, and human errors, each of which contributed in varying degrees to the ultimate consequences of the accident. While evaluations and investigations of the TMI-2 accident continue, activities have been established in the NRC Office of Nuclear Reactor Regulation to ensure the continued safe operation of licensed nuclear power plants.

The Lessons Learned Task Force is one of the several TMI-2 related activities now under way in NRR. The purpose of the Task Force is to identify and evaluate those safety concerns originating with the TMI-2 accident that require licensing actions (beyond those already specified in IE Bulletins and Commission Orders) for presently operating reactors as well as for pending operating license (OL) and construction permit (CP) applications. This includes the review and evaluation of investigative information, staff evaluations of responses to IE Bulletins and Orders, Commissioners' recommendations, ACRS recommendations, staff recommendations, recommendations from NUREG-0560 ("Staff Report on the Generic Assessment of Feedwater Transients in Pressurized Water Reactors Designed by the Babcock \& Wilcox Company"), and recommendations from outside of the NRC. In addition, the Task Force is charged to identify, analyze and recommend changes to 1 icensing requirements and the licensing process for nuclear power plants based on the lessons learned. The scope of the Task Force includes the following general technical areas:

1. Reactor operations, including operator training and licensing;

2. Licensee technical qualifications;

- 3. Reactor transient and accident analysis;

4. Licensing requirements for safety and process equipment, instrumentation, and controls;

5. Onsite emergency preparations and procedures;

6. NRR accident response role, capability and management; and

7. Feedback, evaluation, and utilization of reactor operating experience. 
A related ongoing effort in NRR is the Bulletins and Orders (B\&O) Task Force. It is performing safety evaluations for the five B\&W plants shut down by confirmatory Commission orders, and is reviewing the responses to IE Bulletins by licensees with nuclear steam supply systems (NSSS) designed by Westinghouse, Combustion Engineering, and General Electric.

The B\&0 Task Force plans to publish reports that will cover the various plant designs of each of the reactor vendors noted above. The reports will dea? with specific plant design aspects. The B\&O Task Force is evaluating feedwater transients and small break loss-of-coolant accidents in considerable detail, including the review of emergency procedures and operator training for these events. Thus, the reports of the B\&O Task Force will be more specific in certain areas compared to the more generic actions recommended by the Lessons Learned Task Force. It is anticipated that such reports would be available in the late summer of 1979.

Actions recommended by the Lessons Learned Task Force and approved by the Director of NRR or the Commission, as appropriate, will be assigned to the Divisions of Project Management (DPM), Systems Safety (DSS), and Operating Reactors (DOR) and to the B\&O Task Force for implementation on pending license applications and on operating plants. At that time, appropriate Licensing Boards will be formally notified of these licensing matters.

The short-term actions recommended by the Lessons Learned Task Force in this report, when combined with the requirements associated with implementation of the IE Bulletins on TMI-2, including the generic status reports to be issued by the B\&0 Task Force, are intended to constitute a sufficient set of shortterm requirements to ensure the safety of plants already licensed to operate and those to be licensed for operation in the near future. In addition, commitments from construction permit applicants to meet these requirements are sufficient bases for the staff to recommend the granting of construction permits for those applications now pending before the hearing boards. This set of requirements does not address the questions of offsite emergency preparedness and operator licensing. Recommendations for near-term changes in licensing requirements in these areas are being developed by others and should be considered for application in the pending $C P$ and $O L$ reviews.

Additional licensing actions or requirements may be recommended by the Task Force within the next several months for backfit to operating plants and pending license applications. Other longer term studies or research activities will be recommended by the Lessons Learned Task Force for action by the NRC Offices of Standards Development, Nuclear Regulatory Research, and Inspection and Enforcement as appropriate.

\subsection{Task Force Operation and Coordination}

The Task Force has established communications with the ACRS and its TMI-2 subcommittee, the B\&O Task Force, the Atomic Industrial Forum Steering Committee, the Electric Power Research Institute's Nuclear Safety Analysis Center, and various utility and vendor groups or owner groups, all of which have related interests in the lessons to be learned from the accident at TMI- 2 . 
Coordination with these groups will continue to be an ongoing activity of the Task Force. In addition, the Task Force is coordinating some NRR responses to Congressional inquiries and Commission information requests and work assignments concerning potential changes in reactor regulation resulting from the TMI-2 accident. The Task Force is also advising the Director of NRR on coordination and concurrence matters on the RES, SD, and IE programs connected with TMI-2.

A Targe number of issues has been raised in response to the accident. The initial efforts of the Task Force have been directed mainly to the organizing, screening, and evaluating these issues so that they may be placed into various categories according to their importance to safety and their priority for implementation.

From its first month's work, the Task Force has prepared a set of specific safety requirements recommended for prompt application in short-term operating reactor licensing activities and in near-term $C P$ and $O L$ reviews. These issues have been chosen in the context of a general perspective and a continuing evaluation of the lessons from TMI-2 that can be derived from current understanding of the accident.

The decision-making process followed by the Task Force in determining which safety issues required short-term licensing action versus those that could be deferred for further evaluation by the Task Force or others, was based upon engineering evaluation and qualitative professional judgment of the safety significance of the various issues. In this regard, the Task Force has selected items for "short-term action" if their implementation would provide substantial, additional protection required for the public health and safety. Our recommendations for short-term action are prompt, specific, and safety significant in their character and are not likely to be overturned or contradicted by continuing studies or investigations. Some of them may eventually be displaced, however, by more comprehensive long term changes in nuclear power plant regulation. In some cases, an immediate action may not be amenable to precise description on the basis of information or analyses developed to date; however, the item has been judged by the Task Force to be of sufficient safety significance to require an immediate commitment to get studies or testing underway. In this case the recommended action is to obtain a "short-term commitment" for a longer term modification, study, or test by affected licensees.

The Task Force recommendations for short-term actions or commitments were decided one at a time by a two-thirds majority vote of the Task Force members present. One item is included in this report as a minority recommendation, with its short-term implementation being supported by less than one-third of the Task Force.

Several licensing issues raised by TMI-2 are being examined by other groups within the Commission's staff in coordination with the Lessons Learned Task Force. These are operator training and licensing (OLB), licensee technical qualifications $(Q A B)$, instrumentation to follow the course of an accident (SD), and emergency preparedness (EDO Task Force). These activities can be 
expected to produce significant recommendations for regulatory improvements, some in the next several weeks, others by the end of the summer and beyond.

Having identified and characterized the short-term action recommendations contained in Section 2 of this report, the Task Force will next turn to the broader, more fundamental regulatory questions that must be addressed in the longer term (some of them likely to require evaluations that extend beyond the life span of this Task Force) before further regulatory actions are taken. It is the intent of the Task Force to develop, from its technical and engineering perspective, recommendations on how to proceed with decisions in these fundamental areas, along the lines described in Section 3 of this report.

The Task'Force intends to develop its longer term recommendations and issue a final report by about September 1, 1979. The most important topic to be addressed in that report will deal with issues that will affect the future structure and content of the licensing process.

For several reasons, many of the specific issues raised by TMI-2 cannot be evaluated narrowly. Some issues are inextricably tied to fundamental policy questions that require more thorough deliberation than has been accomplished in the past few weeks. Some of the issues relate to degraded plant conditions or multiple failures that exceed the current design basis derived from existing regulations. Other items require a careful balancing of operations and design considerations in order to achieve a desired improvement. Finally, there are some issues that simply require more study to understand their safety significance.

The fundamental issues requiring work over the long term beyond the life span of this Task Force will generally involve changes in the licensing basis for nuclear plants, and are of a broad-scope integrated or programmatic nature. It is anticipated that decisions on some of these items should await the results of ongoing investigations, such as the President's Commission on TMI-2 and the NRC Special Inquiry, so that the broader perspectives of these groups can be considered. The intent of the Lessons Learned Task Force is to make recommendations on the engineering and licensing considerations that should be factored into those decisions and possible regulatory approaches that could be followed in reaching and implementing the decisions.

\subsection{Implementation of Short-Term Licensing Requirements}

The licensing requirements now being implemented by the $B \& 0$ Task Force have come from the IE Bulletins and Commission Confirmatory Shutdown Orders.

Actions required by the Confirmatory Shutdown Orders on the Babcock \& Wilcox (B\&W) plants are being implemented before each plant is allowed to restart. Licensee responses to the IE Bulletins are presently being reviewed by the $B \& 0$ Task Force, which will issue status reports describing the detailed licensing requirements for the operating plants designed by Westinghouse, Combustion Engineering, and General Electric, as discussed in Section 1.1 of this report. 
The Lessons Learned Task Force has established recommendations in 12 broad areas ( 9 in the area of design and analysis and 3 in the operations area) for change in light water nuclear power plants in the short term. These are described in Section 2, below. The recommendations were discussed with the Regulatory Requirements Review Committee on June 22, 1979, the Commission in a public meeting on June 25, 1979, the TMI-2 Subcommittee of the ACRS, and the ACRS in public meetings on July 11 and 12, 1979. Upon approval by the Director of NRR or the Commission, as appropriate, these short-term items will be transmitted as licensing requirements to licensees and $\mathrm{CP}$ and $\mathrm{OL}$ license applicants. Except as discussed below, the recommended requirements are consistent with existing NRC regulations. Three requirements have been identified, however, that require the revision of present regulations, as follows:

1. Inerting all BWR containments (Section 2.1.5.b),

2. Capability to install a recombiner at each LWR facility (Section 2.1.5.c), and

3. Revision of limiting conditions for operation based on safety system availability (Section 2.2.3).

The first two of the above requirements are governed generally by 10 CFR 50.44 , and the last by 10 CFR 50.36 .

The Lessons Learned Task Force is therefore recommending that, upon approval by the Director of NRR, rulemaking proceedings be initiated on an immediately effective basis. This method of rulemaking will permit the prompt imposition of these requirements and will, with regard to items 1 . and 2 . above, cause existing facilities to comply with the requirements sooner than if a proposed rule were published with or without an advance notice of proposed rulemaking. With regard to item 3 ., the proposed method will provide a new type of information on operating experience at an earlier time. 


\section{SHORT-TERM RECOMMENDATIONS}

The Lessons Learned Task Force has identified 23 specific requirements in 12 areas whose implementation is judged to provide substantial, additional protection which is required for the public health and safety. Each requirement is described in detail in Appendix $A$. They are recommended for promulgation and implementation on the time scale described in Appendix B. The requirements are summarized and listed by general categories below. The summaries are intentionally abbreviated; the requirements are stated in detail in Appendix $A$.

\subsection{Design and Analys is}

\subsubsection{Emergency Power Supply Requirements for the Pressurizer Heaters, Power-Operated Relief and Block Valves, and Pressurizer Level Indicators in PWRs}

A general lesson learned from our review of the TMI-2 accident is that the frequency with which some safety systems, such as the high-pressure safety injection system (part of the Emergency Core Cooling System provided pursuant to General Design Criterion 35 of 10 CFR Part 50, Appendix A), are called upon to function for reactor coolant system pressure or volume control may exceed their generally understood and previously accepted design basis. Other actions pursuant to the Bulletins and Orders applied to B\&W reactors have been aimed at increasing the overall performance reliability of the plants for feedwater transients. This, in turn, decreases the reliance on high-pressure safety injection. Work is also under way in this area by the B\&O Task Force in its review of Westinghouse and Combustion Engineering reactors. Over the long term, additional work is likely to be required in a general review of the frequency of challenges to safety systems based on past operating experience, possibly in the development of acceptable numerical criteria for past and future designs.

For the short term, the Lessons Learned Task Force recommends that the specific changes described below be made in current PWR designs to increase the availability of the reactor pressurizer for pressure control in the event of loss of offsite power, thus decreasing the frequency of challenges to emergency core cooling systems. In some designs, loss of pressurizer heaters due to a loss of offsite power requires the use of the high-pressure emergency core cooling system to maintain reactor pressure and volume control for natural circulation cooling. Similarly, in some designs the inability to close the power-operated relief valve upon loss of offsite power could result in additional challenges to the high-pressure emergency core cooling system. Finally, proper functioning of the pressurizer level instrumentation is necessary to maintain satisfactory pressure control for natural circulation cooling using the pressurizer heaters.

A generic question raised by TMI-2 is the need to expand the applicability of existing reliability criteria to equipment not previously included in the licensing interpretation of equipment designated as "important to safety." The existing criteria for safety equipment include the single-failure criterion, diversity criteria, and other so-called "safety grade" design criteria, such 
as seismic and environmental qualifications. Pending longer term decisions on the need for new safety classifications for such equipment, we recommend that the emergency power supply changes described below be a first required step in that direction.

\section{Recommendation:}

Provide redundant emergency power for the minimum number of pressurizer heaters required to maintain natural circulation conditions in the event of loss of offsite power. Also provide emergency power to the control and motive power systems for the power-operated relief valves and associated block valves and to the pressurizer level indication instrument channe $7 \mathrm{~s}$.

\subsubsection{Performance Testing for BWR and PWR Relief and Safety Valves}

The TMI-2 accident sequence included a failure of a power-operated relief valve to close. This and other operating experience raise a significant question about the performance qualification of two types of valves in the primary coolant boundary; safety and relief valves. The Task Force recommends that programs be promptly initiated and completed prior to July 1981 to establish the functional performance capabilities of PWR and BWR safety and relief valves for normal, transient, and accident conditions. The Task Force is continuing to consider whether there is a need to provide reliability criteria for these and other valves in the primary coolant boundary in implementation of General Design Criterion 14.

\section{Recommendation:}

Commit to provide performance verification by full scale prototypical testing for all relief and safety valves. Test conditions shall include two-phase slug flow and subcooled liquid flow calculated to occur for design basis transients and accidents.

\subsubsection{Information to Aid Operators in Accident Diagnosis and Control}

A widely accepted lesson learned from the TMI-2 accident is that the manmachine interface in some reactor control rooms needs significant improvement. Research and development work in this area is being accelerated in industry and in the NRC research program. However, there is sufficient evidence from TMI-2 evaluations performed to date to conclude that the two following changes should be made, pending results from further studies.

\section{Recommendations:}

a. Direct Indication of Power-Operated Relief Valve and Safety Valve Position for PWRs and BWRs

Provide in the control room either a reliable, direct position indication for the valves or a reliable flow indication devices downstream of the valves. 


\section{b. Instrumentation for Detection of Inadequate Core Cooling for PWRs and BWRs}

Perform analyses and implement procedures and training for prompt recognition of low reactor coolant level and inadequate core cooling using existing reactor instrumentation (flow, temperature, power, etc.) or short-term modifications of existing instruments. Describe further measures and provide supporting analyses that will yield more direct indication of low reactor coolant level and inadequate core cooling such as reactor vessel water level instrumentation.

\subsubsection{Containment Isolation Provisions for PWRs and BWRs}

Evaluation of the containment isolation experience at TMI-2 shows that design features at some other plants may be inadequate in three respects. First, the lack of diverse actuation signals was a contributing factor at TMI-2 in not isolating the containment until after a significant quantity of water had been pumped from the containment sump into the auxiliary building. This is a significant deficiency in some of the older designs and should be corrected. Second, the sequence of events at TMI-2 illustrated the need for careful reconsideration of the isolation provisions of non-essential systems inside containment. Reconsideration should include the identification of those systems that can be isolated indefinitely and those systems that should be selectively isolated only after it is established that they are not essential to continued core cooling or performance of engineered safety features. Third, the experience gained at TMI-2 indicates that the resetting of the containment isolation signal in some designs may result in automatic reopening of some containment isolation valves. Licensees should review their designs and correct this design error if it is found.

\section{Recommendation:}

Provide containment isolation on diverse signals in conformance with Section 6.2.4 of the Standard Review Plan, review isolation provisions for non-essential systems and revise as necessary, and modify containment isolation designs as necessary to eliminate the potential for inadvertent reopening upon reset of the isolation signal.

\subsubsection{Post-Accident Hydrogen Control Systems for PWR and BWR Containments}

The TMI-2 accident resulted in the production of quantities of hydrogen gas in excess of the amounts required by NRC regulations to be considered in the design and accident analysis of nuclear power plants. The Task Force is continuing to study whether the hydrogen design basis needs to be changed. In the interim, we recommend three prompt changes in-requirements to increase the minimum performance criteria currently in place. First, the Task Force recommends a licensing change to improve the reliability of the post-accident hydrogen control systems in all plants. Second, the Task Force recommends a regulation change to 
require containment inerting for all Mark I and Mark II BWRs. The Task Force is continuing to assess the question of whether ice condenser containments should be inerted in the near term. Finally, a minority of the Task Force recommends immediately effective rulemaking to require that changes be made in the operating plants that currently rely upon containment venting as the only method of long-term, post-accident hydrogen removal from the containment. The minority asked that its view be reflected in this report for resolution by the Director of Nuclear Reactor Regulation.

\section{Recommendations:}

a. Dedicated Penetrations for External Recombiner or Post-Accident

For plants that have external recombiners or purge systems, provide dedicated penetrations and isolation systems that meet the redundancy and single failure requirements of the Commission regulations. Modify design as necessary so that these systems are not connected to, or are branch lines of, the large containment purge penetrations.

b. Inerting BWR Containments

Provide inerting for all Mark I and Mark II BWR containments. This would require changes at Vermont Yankee and Hatch Unit 2 (operating plants), as well as pending OL applications for Mark I and II BWRs.

c. Capability to Install Hydrogen Recombiner at Each Light Water Nuclear Power Plant

A minority of the Task Force recommends that all operating reactors, which do not already have the capability, be required to provide the capability to add, within a few days after an accident, a hydrogen recombiner system for post-accident hydrogen control.

\subsubsection{Post-Accident Control of Radiation in Systems Outside Containment of PWRs and BWRs}

At TMI-2, the systems external to the containment building that contained radioactive material had several deficiencies. For example, the licensee had little knowledge of their operational leakage characteristics, and shielding provisions for personnel access were inadequate. The difficulties arose not only in safety systems, but also in systems outside the scope of previous "safety grade" requirements (such as the makeup and letdown system). Pending long-term consideration of the degraded core consequences of the TMI- 2 accident, the Task Force recommends the following steps for operating plants, plants under construction, and plants under $C P$ and $O L$ review so that operators would be in a better position to understand and manage radiation control activities in the event of an accident. 
Recommendations:

a. Integrity of Systems Outside Containment Likely to Contain Radioactive Materials (Engineered Safety Systems and Auxiliary Systems)

Perform leakage rate tests on systems outside containment that process primary coolant and could contain high level radioactive materials. Develop and implement a periodic testing program and preventive maintenance programs.

b. Design Review of Plant Shielding of Spaces for Post Accident Operations

Perform a design review of the shielding of systems processing primary coolant outside of containment. Determine any areas or equipment that are vital for post-accident occupancy or operation and assure that access and performance will not be unduly impaired due to radiation from these systems.

\subsubsection{Improved Auxiliary Feedwater System Reliability for PWRs}

The need for an emergency feedwater system of high reliability is a clear lesson learned from the TMI-2 accident. The IE Bulletins and the Commission's Confirmatory Shutdown Orders for the B\&W designed plants deal with this aspect of the accident in some respects. In addition to the requirements already being implemented by the Bulletins and Orders Task Force, the Lessons Learned Task Force recommends that the following requirements be issued now for Westinghouse and Combustion Engineering designs.

Recommendations:

a. Automatic Initiation of the Auxiliary Feedwater System

Provide automatic initiation of all auxiliary feedwater systems. The initiation signals and circuits shall be designed in such a manner that a single failure will not result in the loss of auxiliary feedwater system function. Testability of the initiating signals and circuits shall be a feature of the design. The initiating signals and circuits shall be powered from the emergency buses. Manual capability to initiate the auxiliary feedwater system from the control room must be retained and must be implemented in such a manner that a single failure in the manual circuits will not result in the loss of system function. The a-c motor-driven pumps and valves in the auxiliary feedwater system must be included in the automatic actuation (simultaneous or sequential) of the loads to the emergency buses. The design of the automatic initiating signals and circuits must be such that their failure will not result in the loss of manual capability to initiate the auxiliary feedwater system from the control room. 
b. Auxiliary Feedwater Flow Indication to Steam Generators

Provide safety-grade indication in the control room of auxiliary feedwater flow for each steam generator. The flow instrument channels shall be powered from the emergency buses, consistent with satisfying the power diversity requirements for auxiliary feedwater systems.

\subsubsection{Instrumentation to Follow the Course of an Accident}

The NRC staff and the ACRS have for some years emphasized the need for special features and instruments to aid in accident diagnosis and control. Although some degree of capability of this type was available at TMI-2, and exists on other plants, the TMI-2 experience shows that more is needed. The Offices of Standards Development and Nuclear Reactor Regulation have agreed to expedite revision of Regulatory Guide 1.97, which deals with this subject area, and its early implementation for all operating plants and plants under construction. It is expected that the necessary revisions would be developed within a few months and implementation would follow soon afterward. In the meantime, the following provisions are recommended for early implementation on all plants to provide a uniform, minimum capability in this area.

\section{Recommendations:}

a. Improved Post-Accident Sampling Capability

Review and upgrade the capability to obtain samples from the reactor coolant system and containment atmosphere under high radioactivity conditions. Provide the capability for chemical and spectrum analysis of high-level samples on site.

b. Increased Range of Radiation Monitors

Provide high range radiation monitors for noble gases in plant effluent lines and a high-range radiation monitor in the containment. Provide instrumentation for monitoring effluent release lines capable of measuring and identifying radioiodine and particulate radioactive effluents under accident conditions.

\section{c. Improved In-Plant Iodine Instrumentation}

Provide instrumentation for accurately determining in-plant airborne radioiodine concentrations to minimize the need for unnecessary use of respiratory protection equipment.

\subsubsection{Analysis of Design and Off-Normal Transients and Accidents}

In the Three Mile Island accident, the performance of important safety systems was degraded due to human errors. Some of the human errors during the TMI accident were caused, in part, by inadequate coordination of transient and accident analysis, emergency procedure preparation, and operator training. 
In its study of the accident, the Task Force has found that, in the past, the full analytical capabilities of the licensees and reactor vendors have not been used in the development of emergency procedures or in the training of reactor operators. Similarly, the NRC review of emergency procedures and operator training has placed little or no emphasis on the appropriateness of the analytical bases of the procedures or training. A substantial improvement in safety can be obtained by improving operator performance during transients and accidents. The Lessons Learned Task Force and Bulletin and Orders Task Force have agreed on the following items as the recommended short-term means of improving operator performance.

\section{Recommendations:}

a. Provide the analysis, emergency procedures, and training to substantially improve operator performance during a small break loss-of-coolant accident.

b. Provide the analysis, emergency procedures, and training needed to assure that the reactor operator can recognize and respond to conditions of inadequate core cooling.

c. Provide the analysis, emergency procedures, and training to substantially improve operator performance during transients and accidents, including events that are caused or worsened by inappropriate operator actions.

\subsection{Operations}

\subsubsection{Improved Reactor Operations Command Function}

The Task Force has concluded that the need for improved operations reliability is the most important lesson learned from the accident at TMI-2. One part of this overall lesson that is amenable to early implementation includes more definitive and clearly articulated operations command responsibilities and improved administrative procedures and controls (to support the command function) for both normal and emergency conditions. Improvements in operator qualifications, training and licensing; technical qualifications of overall reactor operations organizations; and display and system diagnostic equipment will be recommended by NRR and others in the coming months. In the interim, the Task Force recommends prompt implementation of the following administrative changes and controls to significantly improve existing operational capabilities.

\section{Recommendations:}

\section{a. Shift Supervisor Responsibilities}

Review plant administrative and management procedures. Revise as necessary to assure that reactor operations command and control responsibilities and authority are properly defined. Corporate management shall revise and promptly issue an operations policy directive that emphasizes the duties, responsibilities, and authority and lines of command of the control room operators, the shift 
technical advisor, and the person responsible for reactor operations command in the control room (i.e., the senior reactor operator).

b. Shift Technical Advisor

Provide on shift at each nuclear power plant a qualified person (the shift technical advisor) with a bachelor's degree or equivalent in a science or engineering discipline and with specific training in the plant response to off-normal events and in accident analysis of the plant.

Shift technical advisors shall serve in an advisory capacity to shift supervisors. The licensee shall assign normal duties to the shift technical advisor that pertain to the engineering aspects of assuring safe operations of the plant, including the review and evaluation of operating experience.

c. Shift and Relief Turnover Procedures

Review and revise plant procedures as necessary to assure that a shift turnover checklist is provided and required to be completed and signed by the on-coming and off-going individuals responsible for command of operations in the control room. Supplementary checklists and shift logs should be developed for the entire operations organization, including instrument technicians, auxiliary operators, and maintenance personnel.

\subsubsection{Improved In-Plant Emergency Procedures and Preparations}

The Lessons Learned Task Force has confined its initial evaluation of emergency preparedness to the in-plant responsibilities of NRC licensees. Our current understanding of the response of the licensee to the accident at Three Mile Is land shows a need to improve operations procedures and preparations for accident conditions. Pending our further evaluation of these matters and investigations by others, we recommend that the following requirements should be issued now to implement the above recommendations for improving the reactor operations command function.

Recommendations:

\section{a. Control Room Access}

Review plant emergency procedures, and revise as necessary, to assure that access to the control room under normal and accident conditions is limited to those persons necessary to the safe command and control of operations.

b. Onsite Technical Support Center

A separate technical support center shall be provided for use by plant management, technical, and engineering support personnel. In 
an emergency, this center shall be used for assessment of plant status and potential offsite impact in support of the control room command and control function. The center should also be used in conjunction with implementation of onsite and offsite emergency plans, including communications with an offsite emergency response center. Provide at the onsite technical support center the as-built drawings of general plant arrangements and piping, instrumentation, and electrical systems. Photographs of as-built system layouts and locations may be an acceptable method of satisfying some of these needs.

c. Onsite Operational Support Center

Each operating nuclear power plant should establish and maintain a separate onsite operational support center outside the control room. In the event of an emergency, shift support personnel (e.g., auxiliary operators and technicians) other than those required and allowed in the control room shall report to this center for further orders and assignment.

\subsubsection{Revised Limiting Conditions for Operation of Nuclear Power Plants Based} Upon Safety System Availability

The accident at TMI-2 emphasized a previously recognized need to significantly increase operations reliability. The undetected existence of closed isolation valves in the auxiliary feedwater system is exemplary of a kind of human error in reactor operations that must be prevented. Among the many human or operational errors annually reported by the 70 plants now in operation, there are only a few comparable in significance to the defeat of an entire safety function, that is, loss of auxiliary feedwater. However, the fact that operations errors of this magnitude continue to occur at other plants emphasizes the need for improvement. The Task Force recommends prompt action to significantly change the trend of reactor operating experience in this area.

We believe there are two basic approaches for the improvement of reliability of operations: (a) find new ways to effectively require it of the licensees (the requirements have existed, but the implementation has been unsatisfactory), or (b) find new ways to assure it by more effective review and inspection by the NRC staff. In the second approach, the staff could, for example, begin to review and inspect in detail the plant procedures for routine operations, preventive maintenance, surveillance, operations management, and so on. However, the resource implications for the NRC are enormous in view of the sizeable improvement that is indicated as necessary by the accident at TMI- 2 and the fresh view it affords of previous operating experience. Furthermore, it will take a long time for this approach to effect any significant change in operations reliability.

The Task Force recommends the first approach of finding a new way to assure that licensees effectively meet their primary responsibility for reliability of safe operations. To this end we recommend the following immediate rulemaking action, having considered several threshhold levels for its actuation and several alternatives for effecting the NRC decisions it would require. 


\section{Recommendation:}

Require that the Technical Specifications for each reactor provide that the reactor be placed in a hot shutdown condition within 8 hours and in a cold shutdown condition by the licensee within 24 hours of any time that it is found to be or have been in operation with a complete loss of safety function (e.g., loss of emergency feedwater, high-pressure ECCS, low-pressure ECCS, containment, emergency power or other prescribed safety function). Require that an assessment of the cause of the loss of safety function be made (e.g., maintenance, operations error) and that an evaluation of alternative corrective actions be made and documented by the licensee. Require that the senior corporate officer responsible for operation of the facility present the licensee's recommendation for corrective action and evaluation of the alternatives at a public meeting with senior NRC officials. Require that the senior NRC officials issue their decision at that public meeting, or a subsequent public meeting if time is required for staff evaluation, concerning the adequacy of the changes to improve operational reliability proposed by the utility. Allow the facility to return to power only after NRC approval of the changes proposed by the licensee. 


\section{FUTURE WORK BY THE LESSONS LEARNED TASK FORCE}

The licensing requirements discussed in the previous section are intended to address those issues where a short-term improvement in safety can and needs to be made. These requirements are narrow in scope and, with a few exceptions, are consistent with existing regulations, Regulatory Guides, and the staff's Standard Review Plan. The accident at Three Mile Island has raised a number of other significant questions and policy issues. The Task Force will continue its evaluation of the accident by considering broader and more fundamental questions in the design and operation of nuclear power plants and in the licensing process.

The accident at Three Mile Island was not the result of easily identified or isolated design deficiencies or operator errors, but was the consequence of many factors in the design, operation, and licensing of the plant. The Task Force believes that an orderly, comprehensive evaluation of the accident considering the many factors and their interrelationship - is required. Our evaluation will start with the broad, fundamental questions before further specific changes to current requirements are recommended. For convenience of organization, the Task Force has grouped the issues to be considered into four areas: general safety criteria, system design requirements, nuclear power plant operations, and nuclear power plant licensing.

\section{1 General Safety Criteria}

The underlying philosophy of nuclear reactor safety has provided multiple levels of protection against the release of radioactivity, i.e., the concept of defense in depth. It includes diversity and redundancy of various safety functions and systems and multiple physical barriers (the fuel, the cladding, the primary coolant boundary, and the containment). The Task Force concludes that the defense-in-depth concept is sound and is not fundamentally challenged by the occurrence of the accident; however, there is a need to improve the implementation of the concept in determining safety requirements.

The functions and general characteristics of the systems required to provide defense in depth are specified in the General Design Criteria of the Commission regulations (Appendix A to 10 CFR Part 50). The specific design and performance requirements of these systems are determined, generally by analysis, so that the consequences of specified events, such as anticipated operational transients and design basis accidents, are within specific acceptance criteria. At Three Mile Island, some of the safety systems were challenged to a greater extent or in a different manner than was anticipated in their design basis. Many of the events that occurred were known to be possible, but were not previously judged to be sufficiently probable to require consideration in the design basis. Operator error, extensive core damage, and production of a large quantity of hydrogen from the reaction of zircalloy cladding and steam were foreseen as possible events, but were excluded from the design basis, since plant safety features are provided to prevent such occurrences.

The Task Force will consider whether revisions or additions to the General Design Criteria or other requirements are necessary in light of these occurrences. A central issue that will be considered is whether to modify or 
extend the current design basis events or to depart from the concept. For example, analysis of design basis accidents could be modified to include multiple equipment failures and more explicit consideration of operator actions or inaction, rather than employing the conventional single-failure criterion. Alternatively, analyses of design basis accidents could be extended to include core uncovery or core melting scenarios. Risk assessment and explicit consideration of accident probabilities and consequences might also be used instead of the deterministic use of analysis of design basis accidents.

\subsection{System Design Requirements}

The accident at TMI-2 demonstrated disparities between the description and evaluation of accidents in the licensing review of a Safety Analysis Report and the actual response of the plant and its operators. Events occurred that were not foreseen, analyzed, or prepared for. The differences between the actual sequence and those previously analyzed is due in part to regulatory requirements and guidelines. The system design requirements that are an important part of current regulatory requirements should, therefore, be examined in more detail for their adequacy. The system design requirements that are judged to be the most important and have been selected for further study by the Task Force are (a) the single failure criterion, (b) the division between safety grade and nonsafety-grade requirements, (c) operator interactions, and (d) post accident design requirements. These areas are elaborated in the following paragraphs.

In the licensing process, the specification of design basis events has resulted in the classification of systems into two types - safety and nonsafety. The reliability and quality of safety systems are controlled through NRC requirements for their design, construction, and operation. The NRC requirements for nonsafety systems are generally limited to assuring that they do not adversely affect the operation of safety systems. For example, Section 7.7 of the Standard Review Plan states that:

"The control systems not required for safety are acceptable if failures of control system components or total systems would not significantly affect the ability of plant safety systems to function as required, or cause plant conditions more severe than those for which the plant safety systems are designed."

While this general guideline exists for reactor control systems, there are no guidelines that generally apply to the many other nonsafety systems. This results from past judgments as to which systems were needed for transient and accident mitigation. That is, prior to the accident at TMI-2, safety systems were identified in terms of their role in the mitigation of radiological consequences for various postulated design basis events or their importance in assuring safe operations in the event of certain hazards such as earthquakes or fires. The criteria applied to safety equipment include single failure, separation, diversity, seismic resistance, environmental qualifications, testability, etc. Nonsafety systems were assumed to be nonfunctional for mitigation of accidents and no special criteria, other than the one for control systems quoted above, were applied. The Task Force will reassess this approach 
and consider the need to expand the regulatory coverage to other systems such as the power conversion system and the auxiliary systems.

There is another perspective on this question provided by the TMI- 2 accident. At TMI-2, operational problems with the condensate purification system led to a loss of feedwater and initiated the sequence of events that eventually resulted in damage to the core. Several nonsafety systems were used at various times in the mitigation of the accident in ways not considered in the safety analysis; for example, long-term maintenance of core flow and cooling with the steam generators and the reactor coolant pumps. The present classification system does not adequately recognize either of these kinds of effects that nonsafety systems can have on the safety of the plant. Thus, requirements for nonsafety systems may be needed to reduce the frequency of occurrence of events that initiate or adversely affect transients and accidents, and other requirements may be needed to improve the current capability for use of nonsafety systems during transient or accident situations. In its work in this area, the Task Force will include a more realistic assessment of the interaction between operators and systems.

Current regulatory requirements for the design of safety systems specify that no operator action can be credited until a certain period of time after the initiation of a transient or accident. The delay time is intended to account for the time needed by an operator to react to the event, assess the symptoms, and initiate corrective action. The delay time is normally 10 or 20 minutes depending upon the complexity of operator action that is required and the information available to identify the control manipulations. Any actions necessary during the delay time are required to be automatic.

Even though no credit is given for operator action during the delay time, it is possible for the operator to physically accomplish a number of actions. If the actions taken are proper, they can provide a beneficial effect on mitigation of the event. If the operator actions are incorrect, the effectiveness of automatic safety systems can be degraded.

The TMI-2 accident demonstrates that the licensing review requirement of no operator action for a specified period of time is misleading and can be nonconservative. The Task Force will consider how system designs can better account for operator actions.

The accident at TMI-2 also indicates a need for re-examination of design requirements for post-accident operations. The concerns include availability of post-accident monitoring instrumentation, provisions for storage and treatment of large quantities of radioactive liquid and gaseous wastes, and procedures for handling other anticipated post-accident problems on site. The Task Force will review the current regulatory requirements and make recommendations for improvement.

\subsection{Nuclear Power Plant Operations}

Current regulations place responsibility for safety on the licensed utility operating a nuclear power plant. To assure that this responsibility is met, 
criteria for the organization, qualification, and training of the utility staff who operate a plant have been established. At Three Mile Island, the actions of the operations organization, both directly and indirectly, were significant in the cause, course, and consequences of the accident. The Task Force will consider changes to current criteria that could improve both the normal operation of the plant and the response of the plant operating staff to transients and accidents. The Task Force will evaluate means of reducing human errors and improving the quality of operations during normal operation to reduce the frequency of occurrence of situations that could result in or contribute to accidents.

The accident has also raised the question as to whether basic changes are needed in the role of the control room operators in response to of $f$-normal events. Considerations will include: (a) the amount of reliance placed on operator action; (b) the ability of operators to assess the status of the reactor and take corrective action when presented with unusual circumstances; (c) the methods of organization, selection, and training of the people in the operations organization; and (d) improvements in the type, quantity, and method of information display provided to the reactor operators.

The accident also revealed the need to provide specialized technical and other support to the operating staff during the course of an accident. The Task Force will evaluate what support is needed and the planning and preparation necessary to assure that it will be available when necessary.

\subsection{Nuclear Power Plant Licensing}

Although the licensee has the primary responsibility for the safety of a nuclear power plant, the NRC has responsibilities for setting the requirements necessary to provide reasonable assurance that there is no undue risk to the health and safety of the public, and for auditing the design, construction, and operation of plants. The type, depth, and frequency of these audits have varied with time. The Task Force intends to study means of improving the quality of the licensing review process. It will consider increases in the depth of detail of review, improvements in the interaction among staff reviewers and NRC inspectors to provide a more integrated and comprehensive review of license applications, improvements in the continuity of technical review cognizance of the course of reactor construction and operations prior to commercial operations, and improvements in the evaluation and application of operating experience and safety research. One significant issue that will be addressed is that of backfit; that is, the method of determining the need for new requirements and implementing these requirements in a timely manner on reactors already under construction or in operation.

The accident at TMI-2 has shown that the responsibilities and functions of the Office of Nuclear Reactor Regulation under accident conditions should be re-evaluated. Some of the work in this area must await the outcome of other investigations of the agency's performance. However, the Task Force intends to review the NRR role in accident response and to suggest modifications to improve the definition of responsibilities and integration of NRR actions with other organizations. This effort will be coordinated with ongoing efforts in 
other offices of NRC. Recommendations on the content and availability of technical information for NRC and licensee accident response personnel will be considered by the Task Force, including the need and feasibility of acquiring, storing, and transmitting vital plant data from each reactor site. 
APPENDIX A

NRR LESSONS LEARNED TASK FORCE

SHORT-TERM RECOMMENDATIONS 
NRR Lessons Learned Task Force

Short-Term Recommendations

TITLE: Emergency Power Supply Requirements for the Pressurizer Heaters, Power-0perated Relief Valves and Block Valves, and Pressurizer Level Indicators in PWRs (Section 2.1.1)

\section{INTRODUCTION}

Pursuant to NRC regulations in 10 CFR Part 50, Appendix A, the loss of offsite power is considered to be an anticipated operational occurrence $(A O O)$, since it is expected to occur one or more times during the life of a nuclear plant. This event will lead to the loss of main feedwater and loss of forced circulation in the primary coolant system in most of the pressurized water reactor (PWR) plants. Following a loss of offsite power, stored and decay heat from the reactor would normally be removed by natural circulation using the steam generators as the heat sink. Water supply to the steam generators is maintained by the auxiliary feedwater system. Natural circulation cooling of the primary system requires the use of the pressurizer to maintain a suitable overpressure on the reactor coolant system. Alternatively, in the event that natural circulation in the reactor coolant system is interrupted, the feed and bleed mode of reactor coolant system operation can be used to remove decay heat from the reactor. This method of decay heat removal requires the use of the emergency core cooling system (ECCS) and the power-operated relief valves (PORVs) in the pressurizer. Consistent with satisfying the basic requirements in General Design Criteria (GDC) 10,14, 15, 17 and 20 of Appendix A to 10 CFR Part 50, for safety equipment used in mitigation of $\mathrm{AOOS}$, a selected number of pressurizer heaters, the PORVs and associated block valves and level indicators in the pressurizer should be supplied from the emergency power buses.

The failure of the PORVs to reclose following the overpressure portion of the initial transient at TMI-2 was a key factor in the accident. The PORVs can be operated either manually or automatically in most PWR designs. The control circuits for these valves are currently not single failure proof. That is, a single failure in the control circuits or a single operator error can result in a small break loss-of-coolant accident (LOCA). Block valves are provided upstream of the relief valves to isolate such failures. In the event of the loss of offsite power, which in all probability would result in a loss of normal feedwater, the operator would not have the capability to control the operation of the PORVs or to isolate a stuck-open PORV if both the PORV and associated block valves were not powered from the emergency buses.

\section{DISCUSSION}

\section{Power Supply for Pressurizer Heaters}

The reactor coolant system pressure in a PWR plant is normally controlled by using either the pressurizer heaters in the water region of the pressurizer or the spray in the steam region of the pressurizer, plus steam relief for large transients. Pressure control can be accomplished either manually or automatically in all PWR designs. The normal mode of operation of pressurizer 
heaters is automatic. The electrical immersion heaters are located near the bottom of the pressurizer. Some of the heaters are proportionally controlled to correct small pressure variations. The remaining (backup) heaters are turned on when the pressurizer pressure-controlled signal demands approximately 100 percent proportional heater power.

The normal power source for the pressurizer heaters is from a nonsafety-related (non-emergency) bus. However, some PWR plants have the capability of supplying some of the backup heaters from an emergency power source (diesel generators) when loading conditions of the power source permit the manual transfer of this load.

Maintenance of safe plant conditions, including the ability to initiate and maintain natural circulation, depends on the maintenance of pressure control in the reactor coolant system. Pressure control is normally achieved through the use of pressurizer heaters. Experience at TMI-2 has indicated that the maintenance of natural circulation capability is important to safety, including the need to maintain satisfactory natural circulation during an extended loss of offsite power. Without the availability of pressurizer heaters, it may be necessary to operate the high-pressure emergency core cooling system to maintain satisfactory natural circulation conditions. The frequency with which the high-pressure emergency core cooling system is operated may exceed the previously understood and accepted design basis. Therefore, there is a need to consider the upgrading of those pressurizer heaters and associated controls required to maintain natural circulation at hot standby conditions to a safety-grade classification in order to achieve greater heater reliability and to decrease the number of demands for operation of the emergency core cooling system. However, the required number of pressurizer heaters required to maintain natural circulation during transition to cold shutdown needs further evaluation, in the longer term. In the short term, designs should be upgraded to provide the operator with the capability to maintain natural circulation at hot standby through the use of pressurizer heaters when offsite power is not available.

It should be recognized that providing this emergency power capability for a selected number of pressurizer heaters will not preclude challenges to the emergency core cooling system indefinitely after a loss of offsite power. Because of capacity limitations of the seismic Category I water supply and late-in-core-life emergency boration requirements, challenges to the emergency core cooling system may be necessary even when maintaining hot standby conditions. It is believed, however, that providing this emergency power supply capability will reduce challenges to the emergency core cooling system by facilitating natural circulation until offsite power is regained or until one of the two preceding conditions become limiting.

It should also be noted that requirements concerning the design capability for taking the reactor plant from normal operating conditions to cold shutdown conditions, assuming a loss of offsite power, are addressed by Reactor Systems Branch (RSB) Technical Position 5-1 and by Regulatory Guide 1.139 (recently issued for comment). The requirement for emergency power supply to the pressurizer heaters is consistent with Branch Technical Position 5-1 and 
Regulatory Guide 1.139 since the emergency power requirement not only extends the time capability at hot standby but it also may provide a more desirable means of pressure control in the transition to cold shutdown conditions while decreasing the number of challenges to the emergency core cooling system.

Careful attention should be given to assure that the capacity, capability, and reliability of the emergency power source (diesel generators) is not degraded as a result of implementing the capability to supply selected pressurizer heaters from either the offsite power source or the emergency power source when offsite power is not available. Furthermore, appropriate procedures and training will be needed to make the operator aware of when and how the pressurizer heaters should be connected to the emergency buses. The procedures should identify the conditions under which selected emergency loads can be shed from the emergency power source to provide sufficient capacity for the connection of preselected pressurizer heaters. Information required by the operator should be specified to determine what loads can be shed under what conditions as well as the time required to complete load shedding and connection of the heaters to the emergency buses.

Power Supply for Pressurizer Relief and Block Valves

The purpose of the power-operated relief valve (PORV) is to limit the lifting frequency of the ASME Code safety valves by relieving at a lower set point. The PORV is also used to prevent overpressurization of the reactor coolant system during operation at low temperatures, an operational mode when the nil ductility transition temperature (NDTT) becomes a consideration for structural integrity of the primary coolant pressure boundary. In most designs, the PORV can be selected to be operated either manually or automatically. The normal mode of operation of the PORV is automatic. During this mode, the valve opens at a preselected pressure sensed in the reactor coolant system and remains open until the pressure decays to the reseat pressure of the valve. The NDTT protection mode can also be selected, in which case the PORV will open in the event a preselected low-pressure setpoint is reached or reactor temperatures are below the NDTT limit. Manual operation of the PORV can be accomplished from the control room regardless of the reactor coolant system temperature or pressure.

Each PORV line includes a block valve that is located upstream of the relief valve and serves as backup to isolate the PORV line in the event that the relief valve sticks open. Manual operation is the only mode of operation currently in use for the PORV block valves.

The relatively high frequency of A00s places a reliability demand on the operation of the PORVs and associated equipment that is higher than originally envisioned. Also, the operation of some components and systems provided for emergency core cooling have been challenged more times than was previously expected as a result of A00s. Therefore, there is a need to consider the upgrading of the PORVs, block valves, and the associated control and power equipment to a safety-grade classification to achieve greater valve reliability and to minimize the number of challenges to the operation of the emergency core cooling components and systems. However, the merits and degree of upgrading of all pressure-relief equipment associated with the pressurizer 
requires further evaluation, which should be accomplished on a longer term basis. In the short term, the design should be upgraded to provide the operator with the capability to control the operation of the PORVs and associated block valves when offsite power is not available. This capability is essential to mitigate the consequences of transients caused by or resulting from the loss of offsite power.

In addition to the PORVs and associated block valves, there are other valves whose failure to open or close under certain conditions may affect the integrity of the reactor coolant pressure boundary. These valves, as well as the associated control and power equipment, should be evaluated by the NRC staff on a long-term basis to determine whether they should be upgraded to safety-grade classifications or become the subject of specific numerical reliability criteria.

Power Supply for Pressurizer Level Indicators

There is need to have pressurizer level information when offsite power is not available. The pressurizer level indication will be used in conjunction with the pressurizer heaters to maintain pressure control for the reactor coolant system during the natural circulation mode of operation.

\section{POSITION}

Consistent with satisfying the requirements of General Design Criteria 10, 14, 15, 17, and 20 of Appendix A to 10 CFR Part 50 for the event of loss of offsite power, the following positions shall be implemented:

\subsection{Pressurizer Heater Power Supply}

1. The pressurizer heater power supply design shall provide the capability to supply, from either the offsite power source or the emergency power source (when offsite power is not available), a predetermined number of pressurizer heaters and associated controls necessary to establish and maintain natural circulation at hot standby conditions. The required heaters and their controls shall be connected to the emergency buses in a manner that will provide redundant power supply capability.

2. Procedures and training shall be established to make the operator aware of when and how the required pressurizer heaters shall be connected to the emergency buses. If required, the procedures shal 1 identify under what conditions selected emergency loads can be shed from the emergency power source to provide sufficient capacity for the connection of the pressurizer heaters.

3. The time required to accomplish the connection of the preselected pressurizer heater to the emergency buses shall be consistent with the timely initiation and maintenance of natural circulation conditions.

4. Pressurizer heater motive and control power interfaces with the emergency buses shall be accomplished through devices that have been qualified in accordance with safety-grade requirements. 
3.2 Power Supply for Pressurizer Relief and Block Valves and Pressurizer Level Indicators

1. Motive and control components of the power-operated relief valves (PORVs) shall be capable of being supplied from either the offsite power source or the emergency power source when the offsite power is not available.

2. Motive and control components associated with the PORV block valves shall be capable of being supplied from either the offsite power source or the emergency power source when the offsite power is not available.

3. Motive and control power connections to the emergency buses for the PORVs and their associated block valves shall be through devices that have been qualified in accordance with safety-grade requirements.

4. The pressurizer level indication instrument channels shall be powered from the vital instrument buses. These buses shall have the capability of being supplied from either the offsite power source or the emergency power source when offsite power is not available. 
NRR Lessons Learned Task Force

Short-Term Recommendations

TITLE: Performance Testing for BWR and PWR Relief and Safety Valves (Section 2.1.2)

\section{INTRODUCTION}

General Design Criteria 14, 15, and 30 of Appendix A to 10 CFR 50 require that the reactor coolant pressure boundary be designed, fabricated, and erected to the highest quality standards and be tested to ensure an extremely low probability of abnormal leakage, rapidly propagating failure, and gross rupture. These criteria also require that the design conditions of the reactor coolant boundary not be exceeded during any condition of normal operation, including anticipated operational occurrences.

Proper operation of reactor coolant system relief and safety valves is vital for conformance to these design criteria. The inability of a sufficient number of these valves to open could lead to a violation of the integrity of the reactor coolant system pressure boundary. The failure of one or more of these valves to close results in a direct violation of the reactor coolant system pressure boundary integrity.

When the reactor coolant system relief and safety valves open, the flow through these valves is normally saturated steam. Some reactor coolant system transients and accidents as well as alternate core-cooling methods can result in solid-water or two-phase steam-water flow through these valves. Present qualification requirements for these valves include only flow under saturated steam conditions.

The purpose of this recommendation is to require qualification of relief and safety valves under expected operating conditions, which would include solid-water and two-phase flow conditions.

\section{DISCUSSION}

The reactor coolant system relief and safety valves are connected to the pressurizer steam space on PWRs and to the main steam line on BWRs.

On PWRs, transients and accidents that result in increasing reactor coolant system temperatures can cause an expansion of the coolant volume in the reactor coolant system so that the pressurizer fills with water. As the system pressure increases, two-phase and solid-water flow can occur through the reactor coolant system relief and safety valves.

On BWRs, transients or accidents requiring operation of the high-pressure coolant injection system or operation of the reactor core isolation cooling system can result in two-phase or solid-water flow through the relief and safety valves if the reactor vessel level instrumentation malfunctions.

In addition, on both PWRs and BWRs, certain alternative core cooling methods require coolant injection with ECCS systems and coolant discharge through 
relief and safety valves. These cooling methods may result in two-phase or solid-water flow through the relief and safety valves.

Solid-water or two-phase flow through the relief and safety valves can greatly increase the dynamic forces on valve internals, piping, and supports over those that would be expected from saturated steam flow conditions. Present ASME qualification requirements for safety valves include only flow under saturated steam conditions. Because the safety analyses have not given credit for the pressure-relief capability of the power-operated relief valves, the ASME Code also does not address qualification requirements for these valves.

To date, there have been a number of instances of improper operation of relief and safety valves. These examples include valves opening below set pressure, valves opening above set pressure or failure to open, and valves failing to reseat when open. The failure of the power-operated relief valve to reseat was a significant contributor to the TMI-2 sequence of events.

It is not clear whether these past instances of improper operation resulted from inadequate qualification of the valve or from a basic unreliability of the valve design.

Appropriate qualification testing of the relief and safety valves can verify the capability of these valves to function under the required conditions, thereby minimizing the possibility of multiple common-mode failure of these valves due to challenges from conditions for which the valves are not qualified. Qualification testing will also provide some of the information necessary for assessing the basic reliability of the valve design since failures or successes of qualified valves will be a partial indication of valve reliability.

Current valve test facilities may have to be modified or expanded to test valves under various flow regimes since two phase slug flow and solid-water flow regimes will require higher mass flow rates and can result in greater dynamic forces. The time period for completion of this qualification testing has been chosen to allow for modification or expansion of the test facilities. The extended time for completion of this qualification testing is considered appropriate since this testing is considered to be confirmatory of valve performance capability.

It should be noted that this requirement for qualification testing does not include testing under ATWS conditions at this time. Analyses of ATWS events have shown that the pressurizer relief and safety valves could discharge twophase and subcooled water at pressures in the range of $2800 \mathrm{psi}$ to $4800 \mathrm{psi}$ and at temperatures in the range of $650^{\circ} \mathrm{F}$ to $700^{\circ} \mathrm{F}$. It is possible that the final resolution of ATWS in PWRs (expected in calendar year 1980) would permit some plants to reach a peak pressure of 3800 psi subject to showing that the integrity of the primary coolant systems is maintained. It may be prudent, therefore, that test facility modifications include the capability of testing during ATWS conditions since it is likely that adequacy of any ATWS solution would depend on the verification of acceptable valve behavior. 


\section{POSITION}

Pressurized water reactor and boiling water reactor licensees and applicants shall conduct testing to qualify the reactor coolant system relief and safety valves under expected operating conditions for design basis transients and accidents. The licensees and applicants shall determine the expected valve operating conditions through the use of analyses of accidents and anticipated operational occurrences referenced in Regulatory Guide 1.70, Revision 2 . The single failures applied to these analyses shall be chosen so that the dynamic forces on the safety and relief valves are maximized. Test pressures shall be the highest predicted by conventional safety analysis procedures. Reactor coolant system relief and safety valve qualification shall include qualification of associated control circuitry piping and supports as well as the valves themselves. 
NRR Lessons Learned Task Force

Short-Term Recommendations

TITLE: Direct Indication of Power-Operated Relief Valve and Safety Valve Position for PWRs and BWRs (Section 2.1.3.a)

\section{INTRODUCTION}

General Design Criterion 14 of Appendix A to 10 CFR 50 requires that the reactor coolant pressure boundary be designed, fabricated, erected, and tested to have an extremely low probability of abnormal leakage, rapidly propagating failure, and gross rupture. Although the application of this criterion has emphasized the integrity of passive components in the reactor coolant system, such as the reactor vessel and the piping, this criterion should also apply to the valves that provide isolation for the system. Failure of relief and safety valves to close has been the cause of events that result in small break LOCAs. Unambiguous indication of the position of the valves can aid the operator to detect a failure and take proper corrective action.

IEEE-279 requires that, to the extent feasible and practical, protection system input shall be derived from signals that are direct measures of the desired variable. However, only indirect indication of safety or relief valve position is generally provided and can be misleading, as was the case at TMI-2. Although the pressurizer power-operated relief valve was stuck open, control panel lights indicated that the valve was closed because the signal was derived from a sensor of solenoid actuation rather than a sensor of the valve position itself.

The purpose of this position is to provide the operator a more positive indication of valve position and therefore provide additional assurance that the integrity of the reactor coolant pressure boundary can be maintained or a loss of integrity directly diagnosed.

\section{DISCUSSION}

The purpose of relief and safety valves is to operate in conjunction with the reactivity control system to limit system overpressure during anticipated operational transients or accidents. In some PWR plants, additional poweroperated relief valves are provided so that operation of the safety valves is necessary only for the more severe transients or accidents. Since these relief valves are not part of the ASME Code requirements for overpressure protection, they can be and are isolatable with remote-operated block valves.

The consequence of the failure of these valves to close is the loss of coolant and depressurization of the reactor system. Based on incomplete data, there have been five known instances, out of about 230 actuations in about 200 reactor-years of service, of the failure of a relief valve in a PWR to properly close. The failure rate per demand is not significantly different between the three types of PWRs, but the demand rate in the past varied by a factor of ten, from approximately 0.4 to 4.0 demands per reactor-year. In a 11 
instances, except for the one at TMI-2, the consequences were not significant. In BWRs there have been about 53 inadvertent blowdowns due to improper operation of the safety/relief valves located on the steam lines. Incorrect operation of these valves has produced the most frequent losses of primary system integrity. These events, however, were terminated without any violation of a safety limit.

A positive indication of the position of these valves can aid the operator in diagnosing a failure and in taking appropriate corrective action. Thus, the consequences of a failure of these valves can be reduced if the operator can reliably determine that a valve has failed to close. The present methods of indicating the position of safety and relief valves are generally indirect, either by measuring the temperature in the discharge piping or by indicating the status of the operating solenoid. These signals can be ambiguous. Temperature increases with a leaking valve, recovers slowly after a valve actuation and, because the valve discharge lines are sometimes connected to a common header, can increase for all valves when only one is open. Indication of the solenoid position will not, as occurred at TMI, necessarily reveal the position of the valve stem. Direct indication of the valve position, such as a reliable position indication of the valve stem, detection of flow by acoustic methods, or measurement of the flow rate in the discharge pipe, would reduce the ambiguity and aid the operator to take corrective action.

\section{POSITION}

Reactor system relief and safety valves shall be provided with a positive indication in the control room derived from a reliable valve position detection device or a reliable indication of flow in the discharge pipe. 
NRR Lessons Learned Task Force

Short-Term Recommendations

TITLE: Instrumentation for Detection of Inadequate Core Cooling in PWRs and BWRs (Section 2.1.3.b)

\section{INTRODUCTION}

General Design Criterion 13, "Instrumentation and Control," of Appendix A to 10 CFR 50, requires instrumentation to monitor variables "... for accident conditions as appropriate to assure adequate safety." In the past, GDC 13 was not interpreted to require instrumentation to directly monitor water level in the reactor vessel or the adequacy of core cooling. The instrumentation available on some operating reactors that could indicate inadequate core cooling includes core exit thermocouples, cold leg and hot leg resistance temperature detectors (RTDs), in-core neutron detectors, ex-core neutron detectors, and reactor coolant pump current. Generally, such systems were included in the reactor design to perform functions other than monitoring of core cooling or indication of vessel water level.

During the TMI-2 accident, a condition of low water level in the reactor vessel and inadequate core cooling existed and was not recognized for a long period of time. This problem was the result of a combination of factors including an insufficient range of existing instrumentation, inadequate emergency procedures, inadequate operator training, unfavorable instrument location (scattered information), and perhaps insufficient instrumentation.

The purpose of this recommendation is to provide the reactor operator with instrumentation, procedures, and training necessary to readily recognize and implement actions to correct or avoid conditions of inadequate core cooling.

\section{DISCUSSION}

With the hindsight of TMI-2, it appears that the as-designed and fieldmodified instrumentation at Three Mile Island Unit 2 provided sufficient information to indicate reduced reactor vessel coolant level, core voiding, and deteriorated core thermal conditions.

To preclude the failure to recognize such conditions in the future, it is appropriate to address the problem in two stages. The first is based on the detection of reduced coolant level or the existence of core voiding with the existing plant instrumentation. This would include wide range core exit thermocouples, cold leg and hot leg RTDs, coolant inventory control, in-core and ex-core detectors, vessel level (BWR), reactor coolant pump current, and other indications of coolant conditions, including coolant saturation meters (PWR). The second stage is to study and develop system modifications that would not require major structural changes to the plant and that could be implemented in a relatively rapid manner to provide more direct indication than that available with present instrumentation. These changes include PWR vessel level detectors. 
A number of ideas have been discussed for the second stage by the NRC Division of Reactor Safety Research, the ACRS, and the reactor vendors. Some of the possibilities include pressure differential cells, conductivity probes, heated thermocouples, ultrasonic sounding, as well as gamma and neutron void detectors. However, we conclude that detailed engineering evaluation is required before

design requirements for a direct level measurement system can be specified.

\section{POSITION}

1. Licensees shall develop procedures to be used by the operator to recognize inadequate core cooling with currently available instrumentation. The licensee shall provide a description of the existing instrumentation for the operators to use to recognize these conditions. A detailed description of the analyses needed to form the basis for operator training and procedure development shall be provided pursuant to another short-term requirement, "Analys is of Off-Normal Conditions, Including Natural Circulation" (see Section 2.1.9 of this appendix).

In addition, each PWR shall install a primary coolant saturation meter to provide on-line indication of coolant saturation condition. Operator instruction as to use of this meter shall include consideration that is not to be used exclusive of other related plant parameters.

2. Licensees shall provide a description of any additional instrumentation or controls (primary or backup) proposed for the plant to supplement those devices cited in the preceding section giving an unambiguous, easy-to-interpret indication of inadequate core cooling. A description of the functional design requirements for the system shall also be included. A description of the procedures to be used with the proposed equipment, the analysis used in developing these procedures, and a schedule for installing the equipment shall be provided. 
NRR Lessons Learned Task Force

Short-Term Recommendations

TITLE: Containment Isolation Provisions for PWRs and BWRs (Section 2.1.4)

\section{INTRODUCTION}

General Design Criterion 54 of Appendix A to 10 CFR Part 50 requires that piping systems penetrating primary reactor containment be provided with leak detection, isolation, and containment capabilities having redundancy, reliability, and performance capabilities which reflect the importance to safety of isolating the piping systems. Standard Review Plan, Section 6.2.4, "Containment Isolation System," requires that there be diversity in the parameters sensed for the initiation of containment isolation.

Some early plants, including TMI-2, provided automatic containment isolation demand on high containment pressure only (approximately 2 to $5 \mathrm{psig}$ ). For small rates of loss of coolant, there would be little pressure increase in the containment, and automatic containment isolation may be delayed or may possibly not be achieved. The loss of coolant at TMI-2, which produced a small pressure rise in the containment, was accompanied by substantial core damage and a large release of radionuclides into the containment building. Containment isolation was not achieved until approximately 4-1/2 hours after the start of the event. Although this apparently did not lead directly to release of fission products outside containment, it clearly indicated an unacceptable possibility that it could occur.

The purpose of this recommendation is to ensure that effective containment isolation is accomplished and maintained.

\section{DISCUSSION}

Since the purpose of the containment is to provide a final barrier to the release of radioactivity in the event of an accident, isolation of non-essential systems penetrating the containment boundary prior to significant releases from the building is imperative. The TMI-2 event has clearly illustrated the need for selecting diverse parameters to be used for initiation of containment isolation and has shown that a dependance solely on containment pressure rise is inadequate. Current staff requirements (SRP 6.2.4) call for automatic initiation of containment isolation by diverse parameters.

Many plants of earlier vintage have not used diverse parameters for initiation of automatic containment isolation. However, most plants of current design initiate automatic containment isolation upon either safety injection demand or containment high pressure. In some instances, high radiation level in the containment building or ventilation system ducting has been used as a diverse parameter for the initiation of automatic isolation of part or all of the non-essential systems penetrating the containment building.

All containments use a low positive containment pressure for the initiation of automatic containment isolation. Previous LOCA analyses have consistently 
shown that containment pressure will increase rapidly and will reach lowpressure levels that may be used to initiate containment isolation prior to the release of radionuclides resulting from fuel damage for the event being analyzed. For these events, minimum ECCS function has always been assumed. None of these analyses has assumed the failure of emergency core cooling and the subsequent release to containment through such a small vent area as a stuck-open power-operated relief valve as it occurred at TMI- 2 .

The most commonly used second parameter is safety injection demand. Safety injection demand is a safety-grade signal already available through the reactor protection system. Design analyses indicate that safety injection demand is also an early signal of loss of the reactor coolant system integrity and in most cases, when used as a diverse containment isolation signal, will result in earlier initiation of containment isolation than containment high pressure.

Another alternative is the use of high radiation level as a diverse parameter for initiation of containment isolation. Design of a dependable containment isolation signal using radiation detection involves a complex consideration of several factors; i.e., location of detectors versus postulated reactor coolant system (RCS) break locations, dilution factors, trip level set point, etc.

Only two plants have adopted a high radiation level as a safety-grade parameter for the initiation of containment isolation. The use of either a safety injection signal or a properly designed high radiation level as a diverse containment isolation initiator would have assured the early isolation of the containment building at TMI-2.

A second containment isolation problem highlighted by the accident at TMI- 2 is the lack of consistency among plants in the definition of essential and non-essential systems. Systems important to the removal of reactor heat (e.g., reactor coolant pump cooling and seal water) are isolated by the containment isolation signal for some plants. Other plants isolate such systems on another signal, such as containment hi-hi pressure (usually 1/4 to $1 / 2$ of containment design pressure), whereas for others such systems are manually isolated by the operator.

The sequence of events at Three Mile Island has illustrated the necessity for careful consideration of those systems that should be immediately isolated (non-essential systems) and those that should be selectively isolated only after it is established that use of these systems (essential systems) will not be needed. We recommend that all plants reconsider their definition of essential and non-essential systems and provide the NRC with the results of this review. It is our long-term goal to use this information in the development of a consistent set of guidelines for the selection of essential and non-essential systems.

A third containment isolation problem was highlighted by the accident at Three Mile Island Unit 2 and by several of the responses to the Inspection and Enforcement Bulletins. For some plants, the design of containment isolation system controls is such that resetting the isolating signal may cause the containment isolation valves, which were in the open position at the time of automatic containment isolation, to automatically reopen. To prevent this, 
the operator must manually move the individual containment isolation valve controls, or in some cases a ganged control, to the closed position prior to resetting the isolation signal. This design introduces the unnecessary potential for operator error resulting in unexpected releases from the containment building and offsite dose consequences. Such designs should be modified to eliminate the possibility of inadvertent reopening containment isolation valves upon resetting of the isolating signal.

\section{POSITION}

1. All containment isolation system designs shall comply with the recommendations of SRP 6.2.4; i.e., that there be diversity in the parameters sensed for the initiation of containment isolation.

2. All plants shall give careful reconsideration to the definition of essential and non-essential systems, shall identify each system determined to be essential, shall identify each system determined to be non-essential, shall describe the basis for selection of each essential system, shall modify their containment isolation designs accordingly, and shall report the results of the re-evaluation to the NRC.

3. All non-essential systems shall be automatically isolated by the containment isolation signal.

4. The design of control systems for automatic containment isolation valves shall be such that resetting the isolation signal will not result in the automatic reopening of containment isolation valves. Reopening of containment isolation valves shall require deliberate operator action. 
NRR Lessons Learned Task Force

Short-Term Recommendations

TITLE: Dedicated Penetrations for External Recombiners or Post-Accident Purge Systems (Section 2.7.5.a)

\section{INTRODUCTION}

Paragraphs 50.44(d)(2), (3), (f), and (g) of 10 CFR Part 50 and Regulatory Guide 1.7 require the incorporation of hydrogen recombiners or post-accident purge systems for the control of combustible gas concentrations inside containment, depending on the date of the Notice of Hearing for the construction permit (CP) application for the plant. All plants for which the CP hearing notice was published after November 5, 1970, must use hydrogen recombiners for the post-accident control of combustible gas in the containment building. Plants for which the notice of hearing was published prior to November 5 , 1970, may use post-accident purging of the containment for combustible gas control.

The Three Mile Island Unit 2 plant had provisions for post-accident installation and operation of an external hydrogen recombiner for combustible gas contro1. However, the design of the external recombiner hookup at TMI-2 used the 36-inch containment penetrations for the normal containment purge system by tapping 4-inch lines off the purge lines outside the containment building between the building and the outer containment isolation valves. To place the hydrogen recombiner into service required the opening of the inboard 36-inch containment isolation valve in both a containment purge system inlet and outlet line. With this design, once the hydrogen recombiner is put into operation, containment integrity is vulnerable to a single active failure. That is, a spurious or inadvertent opening of one of the 36 -inch outboard containment isolation valves would have resulted in the venting of the containment to the environment. In addition, the design of the system to include use of the large ( 36 -inch) containment purge penetrations resulted in the operation of the recombiner beyond the design capacity of the unit.

The purpose of this recommendation is to institute corrective action for plants that have hookups for external recombiners or post-accident purge systems that are susceptible to single failures like the Three Mile Island Unit 2 design, and/or may result in the operation of the recombiner beyond the design capacity of the unit.

\section{DISCUSSION}

The design of the TMI-2 post-accident recombiner system, including the hookups to the containment building ventilation system, uses the containment penetrations for the normal containment purge system. These are 36 inches in diameter and are sized to handle 25,000 SCFM (standard cubic feet per meter) during containment purging. The post-accident recombiner system has a nominal flow capacity of 65 SCFM and is provided with appropriately sized piping (4 inches in diameter). In using the normal containment purge system penetrations to provide a path to communicate containment atmosphere from the 
containment building through the recombiner and back into the containment building, containment integrity becomes vulnerable to a single failure. The inadvertent or spurious opening of a 36-inch outboard containment isolation valve after the hydrogen recombiner is placed in service could result in the venting of the containment to the environment through a large containment penetration.

The 36-inch containment isolation valves used in the normal containment purge system are butterfly valves. Operating experience with the large butterfly valves typically used in containment purge systems indicates that the frequency with which these valves do not meet local containment leakage technical specification requirements, and thus require corrective maintenance, is higher than the other types of valves typically used as containment isolation valves (e.g., globe, gate, diaphragm). Therefore, the design of the hydrogen recombiner system at TMI-2 not only made the containment integrity vulnerable to a single active failure, but it also required the opening of the inboard isolation valves on two large containment penetrations that could have a marked effect on the containment post-accident leakage performance. During the period that the hydrogen recombiner at TMI- 2 was used, the containment pressure was maintained at a slightly subatmospheric pressure by operation of the containment fan coolers. However, it may not always be possible to maintain a subatmospheric pressure for all possible accidents.

The recombiner hookup at TMI-2 used the 36-inch containment purge system penetrations without providing throttling valves in the recombiner hookup piping. As a result, system pressure drop was lower than that assumed by the designer of the external recombiner. The recombiner therefore operated at about 50 percent beyond its design flow rate and electrical heater input power level operated at about 25 percent above the maximum flow and heater power level for which the unit was tested in the equipment qualification program.

Plants that have low-flow external recombiner systems or post-accident purge systems should reexamine the design of these systems to assure that they are not subject to the same vulnerabilities as the system at TMI-2.

External recombiner systems and post-accident purge systems should be provided with penetrations dedicated to that service only. The containment penetrations should meet the redundancy and single-failure requirements of the Commission regulations for safety-related systems and should be sized to satisfy the flow requirements of the hydrogen recombiner or post-accident containment purge systems. Systems designed to meet these requirements would not present through-line leakage paths between the containment atmosphere and the environment and would eliminate the possibility of violating the containment integrity through a single active failure during hydrogen recombiner or purge system operation.

\section{POSITION}

Plants using external recombiners or purge systems for post-accident combustible gas control of the containment atmosphere should/provide containment isolation systems for external recombiner or purge systems that are dedicated to that service only, that meet the redundancy and single failure requirements of 
General Design Criteria 54 and 56 of Appendix A to 10 CFR Part 50, and that are sized to satisfy the flow requirements of the recombiner or purge system. 
NRR Lessons Learned Task Force

Short-Term Recommendations

TITLE: Inerting BWR Containments (Section 2.1.5.b)

\section{INTRODUCTION}

The designs of light water nuclear power plants are all required by Commission regulations to have the capability to deal with quantities of hydrogen that may be generated during a LOCA from (a) cladding metal-water reaction, (b) corrosion of materials inside containment, and (c) radiolytic decomposition of water. The metal-water reaction source occurs very early in a LOCA whereas the other two are longer term sources. The current regulations (10 CFR 50.44) require that plants be inerted unless they can accommodate the effects of hydrogen that may be released during a LOCA without a loss of safety function. Prior to the promulgation of 10 CFR 50.44, BWR plants using a Mark I type of containment generally had to be inerted to meet this requirement; Vermont Yankee and Hatch 2 are the two operating plants that are exceptions.

The accident at TMI- 2 resulted in a large amount of metal-water reaction in the core and hydrogen generation well in excess of the amounts considered in current Commission regulations.

\section{DISCUSSION}

The current design basis for combustible gas control is given in 10 CFR 50.44, Regulatory Guide 1.7, Revision 2, and Standard Review Plan Section 6.2.5. The requirements set forth conditions on the models and assumptions to be used to calculate the hydrogen source terms; i.e., (a) initial metal-water reaction for the worst-case, design basis loss-of-coolant accident, (b) corrosion of materials, and (c) radiolytic decomposition of water. The implementation requirements for a combustible gas control system are specified in 10 CFR 50.44 .

The requirement for inerting the BWR containments results from earlier versions of Regulatory Guide 1.7 in which the designs were required to accommodate 5 percent metal-water reaction during the LOCA blowdown. The small size of the BWR containments made it necessary to inert these containments to prevent the formation of an explosive mixture. Subsequent changes to Regulatory Guide 1.7 allowed credit for ECCS performance and reduced the amount of metal-water reaction that was required to be considered in the containment design. This led to the decision not to inert Hatch 2 or any of the Mark II BWR plants now in the operating license (OL) review process. The Vermont Yankee plant was not required to be inerted by ruling of the Appeal Board.

For the short term, the experience at TMI-2 does not by itself provide conclusive reason to significantly increase the current design basis for hydrogen control systems. Further study is required regarding the entire design basis for combustible gas control systems and core cooling systems to assure a proper balance of hydrogen prevention and mitigation features. 
However, it is prudent to require inerting of the Vermont Yankee and Hatch 2 containments and all new Mark I and II BWRs.

Inerting of PWR containments is not deemed to be necessary as a short-term requirement because of their larger volumes. Pressurized water reactors with large dry containments normally have 2 to 3 million cubic feet of free volume in the containment building. The PWR ice condenser plants have about 1.25 million cubic feet of free containment volume available. Because they are compartmentalized, they have installed containment air mixing systems. By contrast, the BWR Mark I and II containments have an average free volume of approximatly 300,000 cubic feet. The BWR Mark III containments have also installed containment air mixing systems and have about 1.5 million cubic feet of free containment volume available.

Because of the small volumes of the BWR Mark I and II containments, there is a small margin available to accommodate metal-water reaction. Consequently, there is a greater propensity that a hydrogen concentration in the containment free volume could be greater than the lower limit of flammability in air (4 percent by volume) for a given metal-water reaction. Because of the significantly larger containment volume of the PWR and the BWR Mark III plants, there is a greater capability to accommodate metal-water reaction so that the hydrogen concentration in the containment is much less likely to exceed the lower flammability limit. For example, it requires about 13 percent clad metal-water reaction to reach the flammability limit in an ice condenser and 20 to 30 percent in a large, dry PWR containment, and about 8 percent in a Mark III. Inerting of PWR and Mark III containment buildings is not now judged to be necessary to provide adequate protection for the LOCA source of hydrogen within the containment (metal-water reaction) when considered within the current framework of Commission regulations for post-accident combustible gas control. The Task Force is continuing to study the need for significant increase, in the future, of the percentage of clad metal-water reaction in the hydrogen design basis and the need to require inerting of the ice condenser and Mark III containments.

\section{POSITION}

It shall be required that the Vermont Yankee and Hatch 2 Mark I BWR containments be inerted in a manner similar to other operating BWR plants. Inerting shall also be required for near term OL licensing of Mark I and Mark II BWRs. 
NRR Lessons Learned Task Force

Short-Term Recommendations

TITLE: Capability to Install Hydrogen Recombiner at Each Light Water Nuclear Power Plant (Section 2.1.5.c)

\section{INTRODUCTION}

The current design basis for combustible gas control in the containment building is given in 10 CFR Part 50.44, Regulatory Guide 1.7, Revision 1, and Standard Review Plan Section 6.2.5. Provisions are required to deal with quantities of hydrogen that may be generated during a LOCA accident from (a) clad metal-water reaction, (b) corrosion of materials inside containment, and (c) radiolytic decomposition of water. The current regulations in 10 CFR 50.44 require that a plant be inerted unless it can accommodate hydrogen that may be released during a LOCA. Furthermore, the provisions of 10 CFR $50.44(d)(2),(e),(f)$, and $(g)$ require that light water reactor plants, whose notice of hearing for construction permit applications occurred on or after November 5, 1970, install a recombiner system for long-term post-accident combustible gas control (i.e., hydrogen). For plants whose notice of hearing on applications for construction permits occurred prior to November 5, 1970, combustible gas control measures include a purge and/or repressurization system. In this case, the design basis for the control system would lead to a release of the containment atmosphere for long-term hydrogen control in a matter of weeks to several months, depending upon the containment design. The purpose of the hydrogen recombiner or purge and/or repressurization systems is to deal with the long-term post-accident generation of hydrogen from all sources.

The experience at TMI-2 emphasized the benefit of having a recombiner to cope with the hydrogen generated during the initial core uncovery period as well as that generated during the subsequent post-accident radiolys is of water or corrosion in the reactor vessel and containment. Recombiners of the type currently provided are not capable of preventing the 28 psi (pounds per square inch) containment pressure spike attributed to combustion of hydrogen in the containment building at TMI-2. However, had there not been provisions to use a recombiner at TMI-2, it is possible that for a slightly different accident scenario the containment atmosphere would have required venting for hydrogen control in the week following the accident. It is also possible that the containment may have had to be pressurized with nitrogen over the long term to reduce the hydrogen concentration. Thus, a question for early resolution is whether there should be, in all operating plants, an ability for post-accident hydrogen control other than venting. As previously stated, older plants are not required to have recombiners; thus, if the accident had occurred at another plant, it is possible that venting would have been necessary.

The plants that are not required to have recombiners because of the November 5 , 1970, cutoff date include some presently operating plants and some plants that will soon begin operation that experienced delays in construction. Table A-1 lists about 60 plants without recombiiers. Some older plants have provided recombiners on their own, e.g., Ginna and Calvert Cliffs Units 1 and 2. 
It is recommended by a minority of the Task Force that all plants should incorporate the capability to install a hydrogen recombiner. The majority view is that imposition of an immediate requirement for the use of recombiners at every plant is premature and deserves further evaluation in light of more general questions involving the degraded core consequences experienced at TMI-2.

\section{DISCUSSION}

\section{Minority View}

The safety significance of this recommendation is that a recombiner system can control hydrogen buildup in the containment without venting of the containment atmosphere to the environment. A decision was made at TMI-2 to not release the containment atmosphere to the environment. A number of factors lead to this decision; i.e., the availability of recombiners, the apparent low concentration of hydrogen after the $28 \mathrm{psi}$ pressure spike, and the desire to keep releases to the environment at a minimum. This last factor contradicts the basis for previous NRC rulemaking decisions to not require recombiners at older plants.

The use of a recombiner in the event of a LOCA may not always be required. In some cases (such as a remote site), a purge and repressurization system may be adequate; i.e., purposeful offsite releases do not affect large populations. However, because recombiner technology is well established and is not very costly, the added capability to augment the defense-in-depth principle by providing options to venting for hydrogen control is a prudent public safety measure.

It is the minority viewpoint of the Lessons Learned Task Force that it would be prudent to require that the capability to install a recombiner be backfit to provide means other than venting for control of hydrogen in the containment. This recommendation derives from the premise that the short-term actions of NRC should assure that safety features are available to mitigate the consequences of events similar to TMI-2 that could have the potential for appreciable offsite releases.

\section{Majority View}

The hydrogen problem at TMI- 2 was a short-term situation and fortunately was safely relieved by the apparent combustion of hydrogen in the containment building. The source of this hydrogen was the metal-water reaction of a sizeable fraction of the zircalloy in the core. This amount of hydrogen generation was well in excess of the amount required by the Commission regulations as a design basis for any type of post-accident combustible gas control system.

The basic parameters that establish the capacity of post-accident combustible gas control systems are the long-term decomposition of water due to fission product energy and the corrosion of metals exposed to the chemical action of containment atmosphere and containment sprays. As a result, post-accident combustible gas control systems are designed to process containment air at the 
typical rate of 50 to 100 SCFM and are not required to operate until about a week (minimum) to several months (maximum) after the design bas is accident. The usual parameter used to initiate recombiner operation is a measured containment hydrogen concentration of about 3 to 3.5 volumetric percent hydrogen. The hydrogen recombiner at TMI-2 was put into operation at a time when the measured hydrogen concentration was approximately 2 percent. Current estimates of the maximum hydrogen remaining in solution in the reactor coolant indicate that, even if it were all released to the containment, the hydrogen concentration would not have exceeded 3 percent and would more probably have been less than 2.5 percent. However, site personnel wanted to empty the two waste gas decay tanks back into the containment to try to stop a suspected leak in the waste gas compressor suction line. Because the hydrogen content of the waste gas decay tanks was unknown, site operations personnel wanted the recombiner in operation prior to the slow discharge of the waste gas tanks into the containment. After the recombiners were placed in service, the waste gas decay tanks were only partially emptied into the containment and the repair of the compressor suction line was not attempted.

Information from the work performed by Knolls Atomic Power Laboratory (KAPL) for NRR in the days following the accident indicated that radiolysis should not be adding free hydrogen to the containment. This was attributed to gamma-induced recombinaton of any oxygen formed due to radiolysis of water in a water system rich in dissolved hydrogen, as was the case at TMI-2. In addition, due to the low containment temperatures and the negligible amount of caustic containment sprays the containment spray was operated for only 6 minutes. There should not have been any appreciable generation of hydrogen due to the corrosion of zinc and aluminum. Thus, information was available to indicate that the overall hydrogen concentration in the containment was well below and not likely to approach the design set point for recombiner operation for some appreciable period of time unless the decay tanks were emptied into the containment. An increase in hydrogen over the long term could have been attributed to radiolysis effects; however, actuation of the recombiner to remove the hydrogen prevented a quantitative determination of that hydrogen source.

The course of events at TMI-2 with respect to hydrogen production and control in containment has indicated a need for thorough reconsideration of the Commission's design basis for combustible gas control systems. This should include both a re-examination of the reactor system effects (i.e., coupling the ECCS evaluation and the assumption of hydrogen produced by metal-water reaction) and the acceptability of 10 CFR Part 100 guidelines for evaluation of offsite doses from purposeful releases from the containment. In general, the accident at TMI-2 raises the question of whether the short-term design basis for post-accident combustible gas control systems (metal-water reaction) is underestimated and the long-term design basis (radiolysis and corrosion) is overestimated, resulting in a hydrogen recombiner design that is not capable of providing short-term protection and may not have been needed in the long term.

Because of these considerations, it is the conclusion of the majority of the Lessons Learned Task Force that provisions for the post-accident installation of recombiners should not be required as a short-term action. Such consideration should be part of the long-term reconsideration of the design basis for combustible gas control systems. 
3. POSITION (Minority View)

1. All licensees of light water reactor plants shall have the capability to obtain and install recombiners in their plants within a few days following an accident if containment access is impaired and if such a system is needed for long-term post-accident combustible gas control.

2. The procedures and bases upon which the recombiners would be used on al1 plants should be the subject of a review by the licensees in considering sheilding requirements and personnel exposure limitations as demonstrated to be necessary in the case of TMI-2. 
TABLE A-1. LWR PLANTS WITHOUT RECOMBINER SYSTEMS

BWRs

Dresden 1

Big Rock Point

La Crosse

Oyster Creek 1

Nine Mile Point 1

Humboldt Bay

Dresden 2 \& 3

Millstone 1

Quad Cities 1 \& 2

Browns Ferry 1, 2 \& 3

Monticello

Vermont Yankee

Peach Botton 2 \& 3

Cooper

Pilgrim 1

Hatch 1

Brunswick 1 \& 2

Fitzpatrick

Duane Arnold

Shoreham (OL)
PWRs

Haddam Neck (Conn. Yankee)

San Onofre 1

Yankee Rowe

Point Beach 1 \& 2

Arkansas 1

H. B. Robinson 2

Kewaunee

Oconee $1,2 \& 3$

Crystal River 3

Turkey Point $3 \& 4$

TMI-1

Prairie Island $1 \& 2$

$\mathrm{Ft}$. Calhoun

Diablo Canyon $1 \& 2$ (OL)

Maine Yankee

Davis-Besse 1 
NRR Lessons Learned Task Force

Short-Term Recommendations

TITLE: Integrity of Systems Outside Containment Likely to Contain Radioactive Materials (Engineered Safety Systems and Auxiliary Systems) for PWRs and BWRs (Section 2.1.6.a)

\section{INTRODUCTION}

Parts 20 and 100 of the Commission regulations specify radiation limits and guidelines that must be met by licensed facilities to assure protection of public health and safety. In a power reactor, many systems that will or may handle liquids or gases containing large radioactive inventories after a serious transient or accident are located outside containment. Some systems have technical specification leakage limits established in the plant's operating license, and others do not.

\section{DISCUSSION}

Several of the engineered safety features (ESF) and auxiliary systems (Aux), located outside reactor containment will or may have to function during a serious transient or accident with large radioactive inventories in the fluids they process. The leakage from these systems, when operated, must be minimized or eliminated to prevent the release of significant amounts of radioactive materials to the environment. Examples of such systems include residual heat removal (ESF), containment spray recirculation (ESF), high-pressure injection recirculation (ESF), sampling (Aux), makeup and letdown (Aux), and waste gas (Aux). These systems are checked out during pre-operational testing and startup testing but are not usually included in any periodic leak testing program. It is important that the plant operating staff know the leakage rates of these systems and maintain them at rates that are as low as practical.

Some of these systems were used during the TMI-2 accident with resulting releases of radioactive materials to the auxiliary building ventilation systems. These releases are believed to have resulted from leaking relief valves, waste gas compressor seals, valves, and open rupture discs. The residual heat removal system was not used in its design mode for several reasons, one of which was the uncertainty of the leakage characteristics of the system. Therefore, the lesson learned in this case was that more positive control and knowledge of the leakage rates of these systems is needed to provide the operating staff with the maximum usable equipment and to restrict or control the release of radioactive materials to the environment.

The recommended solution is to make every effort to eliminate or reduce the leakage from these systems, perform periodic tests to assure that the leakage from these systems is maintained as low as practical, and provide the plant staff with current knowledge of the system leakage rates. 
3. POSITION

Applicants and licensees shall immediately implement a program to reduce leakage from systems outside containment that would or could contain highly radioactive fluids during a serious transient or accident to as-low-as-practical levels. This program shall include the following:

1. Immediate Leak Reduction

a. Implement all practical leak reduction measures for all systems that could carry radioactive fluid outside of containment.

b. Measure actual leakage rates with system in operation and report them to the NRC.

2. Continuing Leak Reduction

Establish and implement a program of preventive maintenance to reduce leakage to as-low-as-practical levels. This program shall include periodic integrated leak tests at a frequency not to exceed refueling cycle intervals. 
NRR Lessons Learned Task Force

Short-Term Recommendations

TITLE: Design Review of Plant Shielding of Spaces for Post-Accident Operations (Section 2.1.6.b)

\section{INTRODUCTION}

10 CFR Part 20 and GDC 19, 60, and 64 of Appendix A to 10 CFR Part 50 require the control of radiation exposure associated with plant operations. General Design Criterion 4 requires that systems and components important to safety be designed to accommodate the environmental conditions associated with accidents.

After an accident in which significant core damage occurs, the radiation source terms may approximate those of Regulatory Guides 1.3. and 1.4. In addition, systems that were not designed to contain large radiation sources may become highly radioactive. The resulting radiation fields may make it difficult to effectively perform accident recovery operations or may impair safety equipment.

The purpose of this recommendation is to facilitate post-accident operations using systems that may contain abnormally high levels of radioactivity and to ensure that safety equipment in proximity to the resulting radiation fields is not unduly degraded. Corrective action can consist of design change, additional fixed or portable shielding, post-accident procedure optimization, or equipment upgrading. Systems of interest are identified in recommendation 2.1.6.a.

\section{DISCUSSION}

After an accident in which significant core damage occurs, the radiation source terms may approximate those of Regulatory Guides 1.3 and 1.4. Large radiation fields, resulting form large radiation sources being contained in systems not designed for such activity, may make it difficult to effectively perform accident recovery operations. Such systems, although not specifically identified to perform post-accident functions, may nevertheless be of significant value after an accident. In addition, vital areas such as control rooms, radwaste panels, emergency power supplies, and instrument areas may fall within the radiation fields of such systems.

Post-accident procedures for the use of such vital areas may be all that is necessary. In other instances, additional permanent or temporary shielding may be valuable. For certain cases, it may be prudent to redesign facilities, components or systems. Remote instrument and control capability may also solve some problems.

\section{POSITION}

With the assumption of a post-accident release of radioactivity equivalent to that described in Regulatory Guides 1.3 and 1.4 , each licensee shall perform a radiation and shielding design review of the spaces around systems that may, as a result of an accident, contain highly radioactive materials. The design review should identify the location of vital areas and equipment, such as the 
control room, radwaste control stations, emergency power supplies, motor control centers, and instrument areas, in which personnel occupancy may be unduly limited or safety equipment may be unduly degraded by the radiation fields during post-accident operations of these systems.

Each 1 icensee shall provide for adequate access to vital areas and protection of safety equipment by design changes, increased permanent or temporary shielding, or post-accident procedural controls. The design review shall determine which types of corrective actions are needed for vital areas throughout the facility. 
NRR Lessons Learned Task Force

Short-Term Recommendations

TITLE: Automatic Initiation of the Auxiliary Feedwater System for PWRs (Section 2.7.7.a)

\section{INTRODUCTION}

In recent design reviews since the issuance of the Standard Review Plan, the auxiliary feedwater system (AFWS) is treated as a safety system in a pressurized water reactor (PWR) plant. It is required to satisfy the decay heat removal requirements set forth in General Design Criterion 34 of Appendix A in 10 CFR Part 50. It also plays a significant role in the mitigation of feedwater transients that are anticipated operational occurrences (A00s). In addition, General Design Criterion 20 sets forth requirements for protection systems, including the following: "The protection system shall be designed (1) to initiate automatically the operation of appropriate systems including the reactivity control system, to assure that sicified acceptable fuel design limits are not exceeded as a result of anticipated operational occurrences...."

The need to automaticaliy initiate the operation of the auxiliary feedwater system was not considered essential to safety in the past, and in some plants dependence was placed on the operator to put the system in service when required. Although this need was not emphasized, there are plants in which the initiation of the auxiliary feedwater system is automatic.

Recent analyses of primary system response to feedwater transients and reliability of installed auxiliary feedwater systems establish the need for automatically initiating the auxiliary feedwater system, consistent with satisfying the requirements of $\mathrm{GDC}-20$.

\section{DISCUSSION}

The auxiliary feedwater system is used to supply feedwater to the steam generators during emergency conditions involving loss of the normal feedwater as well as during normal startup, normal shutdown, and hot standby condition. The auxiliary feedwater system initiation time and capacity and the reactor scram time should be such that the water levels in the steam generators being supplied, following loss of main feedwater flow, remain high enough to provide sufficient heat transfer capability to remove stored and residual heat without causing opening of the primary coolant system relief and code safety valves.

Consistent with preventing the steam generators from drying out following loss of main feedwater and minimizing operator errors that could delay the timely initiation of the auxiliary feedwater system in a PWR plant, the auxiliary feedwater system should be automatically initiated in response to a loss of the main feedwater. Equivalent requirements for BWR plants need further evaluation to be accomplished on a long-term basis.

In the short term, as a minimum, control-grade signals and circuits (as defined in Section 3 below) should be used to initiate the auxiliary feedwater system. The initiating circuits should be designed so that a single failure will not 
cause the auxiliary feedwater system to lose its capability to perform as intended. Furthermore, testability of the initiating signals and circuits should be a feature of the design. In the long term, the manual and automatic initiation signals and circuits should be upgraded in accordance with safetygrade requirements. The question of automatic versus manual isolation of the auxiliary feedwater system from the affected steam generator in the event of a steam or feedwater line break requires further evaluation to be accomplished on a long-term basis.

\section{POSITION}

Consistent with satisfying the requirements of General Design Criterion 20 of Appendix A to 10 CFR Part 50 with respect to the timely initiation of the auxiliary feedwater system, the following requirements shall be implemented in the short term:

1. The design shall provide for the automatic initiation of the auxiliary feedwater system.

2. The automatic initiation signals and circuits shall be designed so that a single failure will not result in the loss of auxiliary feedwater system function.

3. Testability of the initiating signals and circuits shall be a feature of the design.

4. The initiating signals and circuits shall be powered from the emergency buses.

5. Manual capability to initiate the auxiliary feedwater system from the control room shall be retained and shall be implemented so that a single failure in the manual circuits will not result in the loss of system function.

6. The a-c motor-driven pumps and valves in the auxiliary feedwater system shall be included in the automatic actuation (simultaneous and/or sequential) of the loads to the emergency buses.

7. The automatic initiating signals and circuits shall be designed so that their failure will not result in the loss of manual capability to initiate the AFWS from the control room.

In the long term, the automatic initiation signals and circuits shall be upgraded in accordance with safety-grade requirements. 


\section{NRR Lessons Learned Task Force}

Short-Term Recommendations

TITLE: Auxiliary Feedwater Flow Indication to Steam Generators

for PWRs (Section 2.7.7.b)

\section{INTRODUCTION}

Since the issuance of the Standard Review Plan, the auxiliary feedwater system in PWR designs has been treated as a safety system. It is used to remove heat from the reactor system when the main feedwater system is not available.

General Design Criterion 13 of Appendix A in 10 CFR Part 50 sets forth the requirements for instrumentation to monitor the variables and systems, over their anticipated ranges of operation, that can affect reactor safety.

Auxiliary feedwater flow indication to the steam generators is considered an important adjunct to the manual regulation of auxiliary feedwater flow to maintain the required steam generator level. Also, the Technical Specifications for PWRs require that the operability and performance of the AFWS be periodically demonstrated under conditions as close to design as practical. Auxiliary feedwater flow indication to the steam generators can be used to verify the functional operability of the AFWS as required by the Technical Specifications.

\section{DISCUSSION}

The inability to reliably detect the lack of auxiliary feedwater flow to the steam generators was an important factor affecting heat removal capability during the early period of the TMI-2 accident. The availability of indication of auxiliary feedwater flow in the control room would have assisted the operator to quickly determine that the pump discharge valves were closed.

Indication of auxiliary feedwater flow to the steam generators will serve to directly verify the actual performance of the AFWS when it is called upon to perform as intended. In addition, in conjunction with the steam generator level indication, the flow measurement can be used to assist the operator in manually maintaining the required steam generator level during auxiliary feedwater system operation.

\section{POSITION}

Consistent with satisfying the requirements set forth in GDC 13 to provide the capability in the control room to ascertain the actual performance of the AFWS when it is called to perform its intended function, the following requirements shall be implemented:

1. Safety-grade indication of auxiliary feedwater flow to each steam generator shall be provided in the control room.

2. The auxiliary feedwater flow instrument channels shall be powered from the emergency buses consistent with satisfying the emergency power diversity requirements of the auxiliary feedwater system set 
forth in Auxiliary Systems Branch Technical Position 10-1 of the Standard Review Plan, Section 10.4.9. 
NRR Lessons Learned Task Force

Short-Term Recommendations

TITLE: Improved Post-Accident Sampling Capability (Section 2.1.8.a)

1. INTRODUCTION

Prompt sampling and analysis of reactor coolant and of containment atmosphere can provide information important to the efforts to assess and control the course of an accident. Chemical and radiological analysis of reactor coolant liquid and gas samples can provide substantial information regarding core damage and coolant characteristics. Analysis of containment atmosphere (air) samples can determine if there is any prospect of a hydrogen reaction in containment, as well as provide core damage information.

No definitive regulatory requirements exist for obtaining and analyzing reactor. coolant samples following an accident. Standard Review Plan Section 9.3, "Process Sampling System," and Section 11.5, "Process and Effluent Radiological Monitoring and Sampling Systems," require that reactor coolant sampling provisions exist; however, no mention of accident conditions is made and, historically, this requirement has been understood to apply only to normal conditions. Standard Review Plan Section 12.5, "Health Physics Program," specifies radiological analysis requirements for liquid and gas samples under "routine" conditions, which does not include major accidents.

Standard Review Plan Section 6.2.5, "Combustible Gas Control in Containment," requires the capability to monitor containment air hydrogen levels under accident conditions. It does not, however, specifically require the capability to obtain and analyze a sample of containment air. Regulatory Guide 1.97, "Instrumentation to Follow the Course of An Accident," addresses on-line instrumentation and does not directly address the acquisition and analysis of liquid or gas samples.

\section{DISCUSSION}

Timely information from reactor coolant and containment air samples can be important to reactor operators for their assessment of system conditions and can influence subsequent actions to maintain the facility in a safe condition. Following an accident, significant amounts of fission products may be present in the reactor coolant and containment air, creating abnormally high radiation levels throughout the facility. These high radiation levels may delay the obtaining of information from samples because people taking and analyzing the samples would be exposed to high levels of radiation. In addition, the abnormally high background radiation, high sample radiation, and high levels of airborne contamination may render in-plant radiological spectrum analysis equipment inoperable during and after an accident.

At TMI-2, all of the above problems were encountered. The licensee was not prepared to obtain and analyze in a timely manner the reactor coolant and containment air samples under accident conditions. The acquisition of reactor coolant and containment air samples was delayed for several days while personnel radiation protection precautions were taken. Once the samples were obtained, 
there were significant delays in the radiological spectrum analysis of the samples. The TMI spectrum analys is equipment was inoperable because of high background radiation; consequently, the samples had to be packaged and flown to a Department of Energy (DOE) laboratory for radiological analysis.

In summary, the radiation at TMI caused by the accident delayed acquisition of information to confirm that significant core damage had occurred. Prompt acquisition and spectrum analys is of reactor coolant samples within several hours after the initial scram would have indicated that significant core damage had occurred; perhaps with such information, earlier remedial actions could have been taken. Similarly, analysis of an early containment air sample would have indicated the presence of hydrogen, significant core damage, and the possibility of a hydrogen explosion in the containment.

\section{POSITION}

A design and operational review of the reactor coolant and containment atmosphere sampling systems shall be performed to determine the capability of personnel to promptly obtain (less than 1 hour) a sample under accident conditions without incurring a radiation exposure to any individual in excess of 3 and $183 / 4$ Rems to the whole body or extremities, respectively. Accident conditions should assume a Regulatory Guide 1.3 or 1.4 release of fission products. If the review indicates that personnel could not promptly and safely obtain the samples, additional design features or shielding should be provided to meet the criteria.

A design and operational review of the radiological spectrum analysis facilities shall be performed to determine the capability to promptly quantify (less than 2 hours) quantify certain radioisotopes that are indicators of the degree of core damage. Such radionuclides are noble gases (which indicate cladding failure), iodines and cesiums (which indicate high fuel temperatures), and non-volatile isotopes (which indicate fuel melting). The initial reactor coolant spectrum should correspond to a Regulatory Guide 1.3 or 1.4 release. The review should also consider the effects of direct radiation from piping and components in the auxiliary building and possible contamination and direct radiation from airborne effluents. If the review indicates that the analyses required cannot be performed in a prompt manner with existing equipment, then design modifications or equipment procurement shall be undertaken to meet the criteria.

In addition to the radiological analyses, certain chemical analyses are necessary for monitoring reactor conditions. Procedures shall be provided to perform boron and chloride chemical analyses assuming a highly radioactive initial sample (Regulatory Guide 1.3 or 1.4 source term). Both analyses shall be capable of being completed promptly; i.e., the boron sample analysis within an hour and the chloride sample analysis within a shift. 
NRR Lessons Learned Task Force

Short-Term Recommendations

TITLE: Increased Range of Radiation Monitors (Section 2.1.8.b)

\section{INTRODUCTION}

Monitors for radioactive effluents are designed to detect and measure releases associated with normal reactor operations and anticipated operational occurrences. Such monitors are required to operate in radioactivity concentrations approaching the minimum concentrations detectable with "state-of-the-art" sample collection and detection methods. These monitors comply with the criteria of Regulatory Guide 1.21 with respect to releases from normal operations and anticipated operational occurrences.

Radioactive gaseous effluent monitors designed to operate under conditions of normal operation and anticipated operational occurrences do not have sufficient dynamic range to function under release conditions associated with certain types of accidents. General Design Criterion 64 of Appendix A to 10 CFR Part 50 requires that effluent discharge paths be monitored for radioactivity that may be released from postulated accidents. The gaseous effluent monitoring system for TMI was evaluated during the licensing review and was found to be adequate for calculated releases from postulated accidents; however, the TMI experience gives rise to a new interpretation of postulated accidents and their associated releases.

The radiation level inside containment is a parameter closely related to the potential for release of radioactive materials in plant effluents. Regulatory Guide 1.97, "Instrumentation for Light-Water-Cooled Nuclear Power Plants to Assess Plant Conditions During and Following an Accident, " requires (for plants whose submittals for construction permit applications were docketed after September 30, 1977) the capability for measuring in-containment radiation levels up to $10^{8} \mathrm{rad} / \mathrm{hr}$.

\section{DISCUSSION}

At TMI-2, the noble gas section of the gaseous radioactive effluent monitor serving the plant vent was designed to measure effluent concentrations up to $10^{-2} \mu \mathrm{Ci} / \mathrm{Cc}(\mathrm{Xe}-133)$. During the initial phases of the accident, noble gas radioactive effluent readings were off scale, with estimates of actual release concentrations calculated to be on the order of $10^{-1} \mu \mathrm{Ci} / \mathrm{cc}$ to $1 \mu \mathrm{Ci} / \mathrm{cc}$.

Similarly, a section of the TMI plant vent gaseous radioactive effluent monitor designed to detect and measure radioiodine releases, while remaining on scale, gave an erroneous indication of high radioiodine content in releases from the vent during the initial phases of the accident. The indication was caused by concentration of short-lived noble gases in the charcoal cartridge, with the presence of the noble gases being read and erroneously interpreted as radioiodine by the monitor readout system.

A similar condition existed in the section of the plant vent monitor designed to detect and measure the presence of particulate radioactive material in 
plant gaseous effluents. In this case, the presence of noble gases in the gas stream passing through the monitor's particulate filter was sufficient to cause the particulate section of the monitor to read off scale and erroneously indicate that large quantities of particulates were being released from the plant vent.

The problem is considered to be generic. A recent survey of existing gaseous effluent monitoring capabilities of operating plants shows that less than 20 percent of operating plants have monitors that would have stayed on scale under the conditions of the TMI accident. It can also be shown, however, that the potential releases from postulated accidents may be several orders of magnitude higher than was encountered at TMI. Under such circumstances, none of the effluent monitors now in service at any operating plant would remain on scale.

A gaseous radiological effluent monitor that does not provide on-scale readings under accident conditions provides only lower-bound information on effluent releases to the environment. A requirement for effluent monitors to have an operating range sufficient to permit on-scale readings under accident conditions is needed to provide meaningful release information for off-site emergency actions.

Three components of gaseous effluents are usually monitored. These are (a) noble gases (for gross activity relative to xenon-133 calibration); (b) radioiodines (usually sampled by collection on charcoal and detected and measured either on the basis of gross gamma activity, which assumes all activity to be iodine-131, or on the basis of a single-channel sodium iodide gamma spectrometer centered on the 0.364 Mev peak of I-131); and (c) particulates (for gross activity collected on a paper or fiber filter relative to a calibration source such as cesium-137).

Under normal operating conditions, a three-component effluent monitoring system is capable of functioning in accordance with design. Readout, under normal operating conditions, provides the plant operator with a reasonably accurate continuous measurement of the actual instantaneous release concentration of noble gases. However, the measurements of radioiodine over a given time period are based on the accumulation of airborne particulates or radioiodine over a given time period in the filter or adsorption media. It is necessary for the plant operator to separately calculate the effluent concentration of interest on the basis of the time rate-of-change of the monitor readout.

(Note: Recent improvements involving the use of microprocessors have made it possible to obtain instantaneous effluent concentrations from integrating-type measurement data by continuous calculation of the time rate-of-change using a built-in computing system.)

The NRC staff recently conducted a survey of installed noble gas effluent monitors at 66 of the 69 operating nuclear units. The survey indicates that nine reactors have effluent monitors whose range exceeds $100 \mathrm{Ci} / \mathrm{sec}$. These monitors would probably have stayed on scale during most of the TMI-2 accident. The remaining reactors have monitors that would have been off scale for various segments of the early days of the accident. Thirty-seven of the 66 reactors have monitors with an upper range that is below $10 \mathrm{Ci} / \mathrm{sec}$. Most of the reactors 
(59 out of 66 ) have monitors with an upper range that exceeds that of the TMI-2 station vent monitor, which was off scale at about $0.5 \mathrm{ci} / \mathrm{sec}$.

Based on data submitted by plant operators, the installed capability exists for monitoring noble gas releases up to a concentration of approximately $1 \times 10^{3} \mu \mathrm{Ci} / \mathrm{cc}$, which is a factor of $10^{5}$ higher than the maximum range of the instrumentation in use of TMI.

The Task Force notes the recent publication of ANSI N320-1978, "Performance Specification for Reactor Emergency Radiological Monitoring Instrumentation," effective December 6, 1978. ANSI N320-1978 recommends an upper detection limit of $10^{5} \mu \mathrm{Ci} / \mathrm{cc}$ for noble gases released to the environs through plant stacks. The staff considers the upper detection limit of $10^{\mathrm{s}} \mu \mathrm{Ci} / \mathrm{cc}$ for noble gases to be technically achievable.

The staff understands that technological problems exist in monitoring of particulates and radioiodines in potential plant releases. Completely satisfactory equipment apparently is not currently available on the commercial market. As previously discussed, the accident condition results in the presence of comparatively large concentrations of short-lived noble gases, which the detectors of the particulate and jodine monitor components "see" as particulates and radioiodines. The problem is further compounded by the preferential adsorption of noble gases in the charcoal cartridges. Although the noble gases are not retained for any substantial period of time, the net effect of a continuous flow of gases through the charcoal cartridge is a localized concentration of noble gases, which is "seen" by the radioiodine detector as radioiodine. Under normal operating conditions, the radioiodine detector is operated as a single-channe 1 gamma spectrometer, focussing on the $0.364 \mathrm{Mev}$ peak of I-131 and rejecting the normally encountered $\mathrm{Xe}-133$ and $\mathrm{Kr}-85$. Under accident conditions, however, the short-lived noble gases are present, several of which emit gamma photons near the 0.364 Mev gamma of I-131, thus being registered as I-131 on the monitor readout. In addition, accident levels of I-13I concentrated on the charcoal cartridge in close proximity to the detector can accumulate to the extent of saturating the detector.

It has been suggested that other adsorbents may be found that would preferentially concentrate the radioiodines, but not the noble gases. If this is found to be practicable, this could somewhat alleviate the radioiodine monitoring dilemma; however, the short-lived noble gases would still be present in the airstream passing through the monitor and the monitor would still give false data. At this time, there are no demonstrated techniques and no currently available equipment that will provide for the desired monitoring of radioiodines or particulates in plant gaseous effluents under accident conditions.

The Task Force concludes that sampling of plant gaseous effluents, with laboratory analysis of samples subsequent to release, is the only valid technique for monitoring accidental releases of radioiodines and particulates. In the absence of valid on-line monitoring capability for accident-level releases of radioiodines and particulates, we strongly urge that research be undertaken promptly to develop such capability. 
The Task Force is working with other members of the NRC staff to urge that the NRC promptly adopt ANSI N320-1978 in its entirety, including those provisions dealing with radiation measurements in containment and other plant buildings, airborne radioactivity measurements within the plant, and airborne radioactivity measurements and radiation measurements in the environment. Implementation of the standard should take place as soon as practical for those criteria consistent with available equipment. It is further urged that research programs be established for development of instrumentation and equipment to meet the criteria that cannot be met by currently available equipment. The mechanisms suggested for implementation include adoption by reference of certain criteria in a revision to Regulatory Guide 1.97 and preparation of one or more additional Regulatory Guides to implement the remaining criteria.

At TMI-2, the radiation monitor in containment had a range capacity of $10^{6} \mathrm{rad} / \mathrm{hr}$, which was adequate to meet the conditions of the accident. In reviewing the monitoring capabilities of other plants, however, it is found that there are few operating plants with instrumentation capable of measuring levels in excess of $10 \mathrm{rad} / \mathrm{hr}$. During the initial post-accident period at TMI, questions arose as to the validity of the instrument readout and to the operational characteristics of the instrument under the accident environment. The Task Force considers that the in-containment high-level monitoring instrumentation at TMI-2 was adequate to measure the existing radiation levels; however, it also considers that such instrumentation should consist of at least two channels, each separated physicaliy from the other, and that the instrumentation system should be qualified to the design criteria for safety-grade instrumentation. Furthermore, the in-containment radiation monitor should be capable of measuring radiation up to $10^{8} \mathrm{rad} / \mathrm{hr}$, as currently required in Regulatory Guide 1.97. The Task Force also recommends that the instrumentation described above be required for all operating plants and for all plants now under construction.

\section{POSITION}

The requirements associated with this recommendation should be considered as advanced implementation of certain requirements to be included in a revision to Regulatory Guide 1.97, "Instrumentation to Follow the Course of an Accident," which has already been initiated, and in other Regulatory Guides, which will be promulgated in the near-term.

1. Noble gas effluent monitors shall be installed with an extended range designed to function during accident conditions as well as during normal operating conditions; multiple monitors are considered to be necessary to cover the ranges of interest.

a. Noble gas effluent monitors with an upper range capacity of $10^{5} \mu \mathrm{Ci} / \mathrm{cc}(\mathrm{Xe}-133)$ are considered to be practical and should be installed in all operating plants.

b. Noble gas effluent monitoring shall be provided for the total range of concentration extending from a minimum of $10^{-7} \mu \mathrm{Ci} / \mathrm{cc}$ $(\mathrm{Xe}-133)$ to a maximum of $10^{5} \mu \mathrm{Ci} / \mathrm{cc}(\mathrm{Xe}-133)$. Multiple monitors are considered to be necessary to cover the ranges of interest. The range capacity of individual monitors shall overlap by a factor of ten. 
2. Since iodine gaseous effluent monitors for the accident condition are not considered to be practical at this time, capability for effluent monitoring of radioiodines for the accident condition shall be provided with sampling conducted by adsorption on charcoal or other media, followed by onsite laboratory analysis.

3. In-containment radiation level monitors with a maximum range of $10^{8} \mathrm{rad} / \mathrm{hr}$ shall be installed. A minimum of two such monitors that are physically separated shall be provided. Monitors shall be designed and qualified to function in an accident environment. 
NRR Lessons Learned Task Force

Short-Term Recommendations

TITLE: Improved In-Plant Iodine Instrumentation (Section 2.1.8.c)

\section{INTRODUCTION}

10 CFR Part 20 provides criteria for control of exposures of individuals to radiation in restricted areas, including airborne iodine. Since iodine concentrates in the thyroid gland, airborne concentrations must be known in order to evaluate the potential dose to the thyroid. If the airborne iodine concentration is overestimated, plant personnel may be required to perform operations functions while using respiratory equipment, which sharply limits communication capability and may diminish personnel performance during an accident. The purpose of this recommendation is to improve the accuracy of measurement of airborne iodine concentrations within nuclear power plants.

\section{DISCUSSION}

The concentration of iodine in atmospheric air is determined by measuring the activity of iodine adsorbed in a carbon filter through which air has been pumped. The charcoal filter is removed from the air pump and allowed to ventilate to permit the noble gases to diffuse to the atmosphere. The filter is then counted for radioactivity content and the remaining activity is ascribed to iodine. This procedure is conservative; however, it is possible for sufficient noble gas to be adsorbed in the charcoal so that the resulting iodine determination may be unduly conservative (high). This was the case at Three Mile Island. Because the iodine concentration was greatly overestimated, plant personnel performed their operations functions using respiratory equipment when such use was not necessary. Actual iodine concentrations apparently were below levels requiring such protective actions. One acceptable method to eliminate this problem is to measure the iodine by gamma energy spectrum analysis. Equipment for such measurements is commercially available.

\section{POSITION}

Each licensee shall provide equipment and associated training and procedures for accurately determining the airborne iodine concentration throughout the plant under accident conditions. 
NRR Lessons Learned Task Force

Short-Term Recommendations

TITLE: Analysis of Design and Off-Normal Transients and Accidents (Section 2.1.9)

\section{INTRODUCTION}

The design requirements for the Emergency Core Cooling System (ECCS) are stated in 10 CFR Part 50.46. Each applicant for a CP or OL must show compliance with these requirements through analyses that are prescribed in Appendix $K$ to 10 CFR Part 50. The design requirements for other important safety systems, such as the reactor coolant system pressure boundary and the reactor protection system, are stated in the General Design Criteria in Appendix A to 10 CFR Part 50. The required analyses to show compliance with the General Design Criteria are stated in Section 15 of Regulatory Guide 1.70 ("Standard Format and Content of Safety Analysis Reports for Nuclear Power Plants"). These are requirements for the analysis of the so-called "design basis events" which comprise various anticipated transients and postulated accidents.

Although the analyses listed above are primarily intended to show acceptable performance and design of various safety systems, they have also been used for developing emergency procedures and operator training. These other uses of analyses are not addressed in the NRC Standard Review Plans, and the analytical basis for emergency procedures has therefore not been generally reviewed by NRC. The emergency procedures are audited by the office of Inspection and Enforcement; however, NRC does not perform a formal technical review of all procedures, or evaluate which analyses were used to develop them.

The experience of the TMI-2 accident indicates that further analyses of transients and small LOCAs are needed. These conclusions, including the coordination of the results of analyses and emergency procedures, were discussed in NUREG-0560, "Staff Report on the Generic Assessment of Feedwater Transients in Pressurized Water Reactors Designed by the Babcock \& Wilcox Company."

In the Three Mile Island accident, a loss of feedwater transient led to a small break loss-of-coolant accident when the pilot-operated relief valve failed to close. The emergency procedure for a loss of feedwater did not alert the operators to this possibility, nor did it provide any indication that the opening of the PORV should have been expected. In addition, recent reviews of emergency procedures for the small break loss-of-coolant accident at B\&W plants clearly indicate that the procedures were inadequate to provide the operators with needed instructions on actions required to cope with various sizes and locations of small breaks. It is clear from the events at Three Mile Island that operator training and emergency procedures were not adequate for the operators to conclude from the information available that the reactor core was uncovered and inadequately cooled for a long period of time.

The purpose of the recommended action is to provide a substantial increase in safety by improving the performance of reactor operators during transient and accident conditions. Substantive short-term improvement can be made through a combination of analyses, improved procedures, and improved training. 


\section{DISCUSSION}

The Three Mile Island event is an example of an accident in which the performance of important safety systems was degraded due to human errors. This is an indication that human errors are a significant factor in the unavailability of needed safety systems. This appears to result from inadequate coordination between the organizations providing the system design and analysis and the organizations developing the emergency procedures and providing the operator training. The staff has looked broadly at this problem since the accident. In some cases, the NSSS vendor does not supply any guidelines on the development of emergency procedures. Even for those cases in which guidelines are supplied, the guidelines are usually based on the transient and accident analyses from Section 15 of the Final Safety Analysis Report used in the licensing design review. This is not satisfactory since the Section 15 FSAR analyses are performed to demonstrate the acceptability of various system designs pursuant to specific and prescriptive design basis events derived from the Commission regulations. More and a different kind of analysis is needed for use in developing emergency procedures and operator training. For example, the FSAR design analysis of the loss of feedwater transient for Three Mile Island assumed that the PORV did not open. This assumption led to the highest calculated pressure and was therefore appropriate for a design calculation. However, as a result of not analyzing the expected response of the PORV, the emergency procedure for a loss of feedwater did not acknowledge that the PORV would open. Moreover, it did not indicate when PORV closure should have been expected or that it was important to verify PORV closure. Prior to TMI-2, the NRC staff had never reviewed plant operating procedures or emergency procedures for conformance to expected plant response in transient or accident situations. On the basis of our review of this area since the accident, we find several important kinds of deficiencies that require correction.

A substantial improvement in safety can be obtained by improving operator performance during transients and accidents. The following steps are required in order to accomplish this objective: (a) analyze to predict plant response during abnormal occurrences and to identify proper and improper operator actions associated with important safety considerations (such as prevention of core uncovery, establishing natural circulation, and prevention of more serious accidents); (b) prepare guidelines for emergency procedures; (c) implement improvements in emergency procedures; and (d) retrain operators.

We have established the following priorities for the short term:

1. Analysis of small break loss-of-coolant accidents;

2. Analysis of the symptoms of inadequate core cooling and required actions to restore core cooling; and

3. Analysis of transient and accident scenarios including operator actions not previously analyzed.

The efforts related to small breaks have been completed for B\&W plants and are well under way for other plants. This effort is being accomplished by the Bulletins and Orders Task Force and does not require additional input from the 
Lessons Learned Task Force. The analysis of inadequate core cooling will provide information in an area in which the operators presently may have no procedures or training. This effort will provide defense in depth because it will inform the operators and call for appropriate corrective action if system failures or operator errors lead to a situation of inadequate core cooling. Specific analysis to be performed are addressed in the next section. The third priority short-term effort is related to analysis of transients and accidents to identify operator actions (to be required or to be prohibited) associated with important safety considerations (such as natural circulation, prevention of more serious accidents, and prevention of core uncovery). Each of the short-term efforts is related to improving emergency procedures and improving operator training. Additional analyses will be required in the long term.

Additional small break calculations are being performed in the near term following the Three Mile Island accident. These calculations will support changes in emergency procedures to cover the full spectrum of small breaks. The question of compliance with 10 CFR Part 50 Appendix $K$ requirements for the full spectrum of small breaks has not been addressed in the short term, but should be addressed in the long term. In addition, reconsideration of the appropriateness of the single-failure criterion may lead to the need for more analyses in the long term.

\section{POSITION}

Analyses, procedures, and training addressing the following are required:

1. Small break loss-of-coolant accidents;

2. Inadequate core cooling; and

3. Transients and accidents.

Some analysis requirements for small breaks have already been specified by the Bulletins and Orders Task Force. These should be completed. In addition, pretest calculations of some of the Loss of Fluid Test (LOFT) small break tests (scheduled to start in September 1979) shall be performed as means to verify the analyses performed in support of the small break emergency procedures and in support of an eventual long term verification of compliance with Appendix $K$ of 10 CFR Part 50.

In the analysis of inadequate core cooling, the following conditions shall be analyzed using realistic (best-estimate) methods:

1. Low reactor coolant system inventory (two examples will be required LOCA with forced flow, LOCA without forced flow).

2. Loss of natural circulation (due to loss of heat sink).

These calculations shall include the period of time during which inadequate core cooling is approached as we 11 as the period of time during which inadequate core cooling exists. The calculations shall be carried out in real time far 
enough that all important phenomena and instrument indications are included. Each case should then be repeated taking credit for correct operator action. These additional cases will provide the basis for developing appropriate emergency procedures. These calculations should also provide the analytical basis for the design of any additional instrumentation needed to provide operators with an unambiguous indication of vessel water level and core cooling adequacy (see Section 2.1.3.b in this appendix).

The analyses of transients and accidents shall include the design basis events specified in Section 15 of each FSAR. The analyses shall include a single active failure for each system called upon to function for a particular event. Consequential failures shall also be considered. Failures of the operators to perform required control manipulations shall be given consideration for permutations of the analyses. Operator actions that could cause the complete loss of function of a safety system shall also be considered. At present, these analyses need not address passive failures or multiple system failures in the short term. In the recent analysis of small break LOCAs, complete loss of auxiliary feedwater was considered. The complete loss of auxiliary feedwater may be added to the failures being considered in the analys is of transients and accidents if it is concluded that more is needed in operator training beyond the short-term actions to upgrade auxiliary feedwater system reliability. Similarly, in the long term, multiple failures and passive failures may be considered depending in part on staff review of the results of the short-term analyses.

The transient and accident analyses shall include event tree analyses, which are supplemented by computer calculations for those cases in which the system response to operator actions is unclear or these calculations could be used to provide important quantitative information not available from an event tree. For example, failure to initiate high-pressure injection could lead to core uncovery for some transients, and a computer calculation could provide information on the amount of time available for corrective action. Reactor simulators may provide some information in defining the event trees and would be useful in studying the information available to the operators. The transient and accident analyses are to be performed for the purpose of identifying appropriate and inappropriate operator actions relating to important safety considerations such as natural circulation, prevention of core uncovery, and prevention of more serious accidents.

The information derived from the preceding analyses shall be included in the plant emergency procedures and operator training. It is expected that analyses performed by the NSSS vendors will be put in the form of emergency procedure guidelines and that the changes in the procedures will be implemented by each licensee or applicant.

In addition to the analyses performed by the reactor vendors, analyses of selected transients should be performed by the NRC Office of Research, using the best available computer codes, to provide the basis for comparisons with the analytical methods being used by the reactor vendors. These comparisons together with comparisons to data, including LOFT small break test data, will constitute the short-term verification effort to assure the adequacy of the analytical methods being used to generate emergency procedures. 
NRR Lessons Learned Task Force

Short-Term Recommendations

TITLE: Shift Supervisor's Responsibilities (Section 2.2.1.a)

\section{INTRODUCTION}

Section 50.54 of 10 CFR Part 50, "Conditions of Licenses," specifies in paragraph (k) that the licensee shall designate individuals to be responsible for directing the licensed activities of licensed operators. These individuals shall be 1 icensed as senior operators pursuant to 10 CFR Part 55 . The scope of the examination for a senior operator is similar to that for an operator with emphasis placed on a higher degree of competence and a wider and more thorough knowledge of administrative controls, facility license, Technical Specifications, and provisions of applicable regulations. In practice, the senior operator who directs the activities of licensed operators is called a shift supervisor (in some organizational structures, a shift engineer). Shift supervisors have responsibility for the safe operation of the plant on their assigned shifts.

The ability of shift supervisors to carry out their responsibility for safe operation of the plant may be impaired by actions of utility management or by the individuals themselves. For example, management can impair a shift supervisor's command function by requiring a significant portion of his time to be devoted to administrative functions. The shift supervisor's command function can also be impaired by failure to recognize his leadership and decisionmaking responsibilities which go beyond those of the operators. If neither management nor the individual shift supervisors treat the shift supervisor position as that of a "manager" or "commander" of shift operations, the benefits to safety of clear delineation of a responsible individual in charge of plant operations may be reduced.

The purpose of this recommendation is to re-emphasize the command and control function of the shift supervisor in the safety of operations in both normal and off-normal conditions.

\section{DISCUSSION}

The day-to-day routine of many shift supervisors has become increasingly devoted to administrative details. Instead of providing direct, command oversight of operations and performing management review of ongoing operations in the plant that are important to safety, they find some of their time devoted to lesser chores. Their activities can range from the scheduling of overtime and meal money to review of radiation work permits, maintenance requests, checklists, and surveillance procedures.

Many shift supervisors have attained their position after having served for a number of years as a control room operator; that is, a direct manipulator of plant controls. Although the training received by senior operators is directed at increasing their technical understanding and knowledge of administrative controls of operations, no real emphas is is placed on their management or command role. 
The safety significance of this situation may have been a factor in the accident at TMI-2. In the early stages of the accident, the shift supervisor apparently became involved in a particular set of manipulations being performed at one section of the console. Later during the accident he left the control room to address a particular problem elsewhere in the plant. These actions are characteristic of an operator's role. The command or management role is to maintain an overview of the situation, to make decisions, and to direct operations.

The training and selection of shift supervisors should be redirected to emphasize this command and control function.

The physical size of a nuclear power plant control room precludes a direct analogy with aircraft. In an airplane, the controls are within arms' reach of the pilot. Thus, the pilot analyzes the situation and makes corrective manipulations. However, to use a limited analogy, the nuclear power plant shift supervisor should be trained and required to supply the pilot's thinking and decision making and to delegate the necessary control manipulations to the console operators.

\section{POSITION}

1. The highest level of corporate management of each licensee shall issue and periodically reissue a management directive that emphasizes the primary management responsibility of the shift supervisor for safe operation of the plant under all conditions on his shift and that clearly establishes his command duties.

2. Plant procedures shall be reviewed to assure that the duties, responsibilities, and authority of the shift supervisor and control room operators are properly defined to effect the establishment of a definite line of command and clear delineation of the command decision authority of the shift supervisor in the control room relative to other plant management personnel. Particular emphasis shall be placed on the following:

a. The responsibility and authority of the shift supervisor shall be to maintain the broadest perspective of operational conditions affecting the safety of the plant as a matter of highest priority at all times when on duty in the control room. The idea shall be reinforced that the shift supervisor should not become totally involved in any single operation in times of emergency when multiple operations are required in the control room.

b. The shift supervisor, until properly relieved, shall remain in the control room at all times during accident situations to direct the activities of control room operators. Persons authorized to relieve the shift supervisor shall be specified.

c. If the shift supervisor is temporarily absent from the control room during routine operations, a lead control room operator shall be designated to assume the control room command function. These temporary duties, responsibilities, and authority shall be clearly specified. 
3. Training programs for shift supervisors shall emphasize and reinforce the responsibility for safe operation and the management function the shift supervisor is to provide for assuring safety.

4. The administrative duties of the shift supervisor shall be reviewed by the senior officer of each utility responsible for plant operations. Administrative functions that detract from or are subordinate to the management responsibility for assuring the safe operation of the plant shall be delegated to other operations personnel not on duty in the control room. 
NRR Lessons Learned Task Force

Short-Term Recommendations

TITLE: Shift Technical Advisor (Section 2.2.1.b)

\section{INTRODUCTION}

Paragraph 50.34(b)(6)(i) of 10 CFR Part 50, "Licensing of Production and Utilization Facilities," requires that applications for a license to operate a nuclear power plant include information concerning organizational structure, personnel qualifications, and related matters. Regulatory Guide 1.8 describes a method acceptable to the NRC staff of implementing this portion of the Commission's regulations with regard to personnel qualifications. The experience gained from the TMI-2 accident indicates the need for more specific details with regard to the availability and training of qualified technical support personnel to the operations organization in the event of an accident.

The purpose of this recommendation is to provide professionally qualified technical support by the addition of an individual on shift, with training in nuclear engineering or a related science and training in plant design and transient response, to complement the control manipulation, event diagnosis, and operations management functions of other shift operations personnel.

\section{DISCUSSION}

For an off-normal event in reactor operations, the shift supervisor's primary responsibility is the command and control function. The other control room operators assumed a manipulative, reactionary role in response to commands from the shift supervisor and in response to the various alarms and other indicators of plant conditions caused by the event. Having reviewed the facts available on the accident at TMI-2 and the general state of training and qualifications for present operators and senior operators, the Task Force has concluded that additional technical and analytical capability, dedicated to concern for the safety of the plant, needs to be provided in the control room to support the diagnosis of off-normal events and to advise the shift supervisor on actions to terminate or mitigate the consequences of such events.

To provide this additional technical and analytical support for the operations staff, the Task Force has considered several alternatives:

1. Upgrade the requirements for operators and senior operators to include more engineering and plant response training;

2. Provide additional on-shift personnel with science or engineering training and specific training in plant design and response;

3. Provide on-call assistance to the control room by identified and personnel in the plant engineering organization having the training in item 2., above; and

4. Improve plant response diagnosis capabilities by backfit of computer and plant status display innovations. 
The first and fourth alternatives have merit, and future revisions and upgrading of operator training and qualification requirements and of control room computers and informational displays are intended to accomplish similar objectives in the long term. However, such changes would not provide the dedicated safety monitor aspects of a properly chosen and qualified shift technical advisor.

The second alternative is the short-term action recommended by the Task Force. Supplemental, on-shift technical support personnel should be provided in the form of a shift technical advisor. We consider the third alternative to be unacceptable because of the safety significance and high potential value of the input a technical advisor could provide in the early reaction to an off-normal event.

In addition to a bachelor's degree or equivalent in a science or engineering discipline, the shift technical advisor should have specific training in the response and the analysis of the particular plant for transients and accidents. Shift technical advisors should also receive training in the structures, systems, and component design and layout of the plant, including training in the functions and capabilities of instrumentation and controls in the control room. The Task Force believes it should be optional for licensees to choose whether the shift technical advisors are trained or licensed as reactor operators or senior operators. In any event, when assigned as shift technical advisor, these personnel are to have no duties or responsibilities for manipulation of controls or command of operations.

The shift technical advisor would report to the shift supervisor in the control room during off-normal reactor plant conditions. It should be emphasized that the role of the shift technical advisor is to serve in an advisory capacity to the shift supervisor and not to assume command or control functions. The shift supervisor may choose to direct the shift technical advisor to perform his advisory role from either the control room or the onsite technical support center, or the shift supervisor may direct the shift technical advisor to serve as a liaison between technical support personnel manning the onsite technical support center and the shift supervisor (see Section 2.2.2.b).

Routine duties and assignments of the shift technical advisor should include matters involving engineering evaluation of day-to-day plant operations from a safety point of view.

Suggested assignments to accomplish this objective include:

1. Engineering evaluation of the operating history of the plant (equipment failures, design problems, operations errors, etc.) and Licensee Event Reports from other plants of similar design, with suitable dissemination of the results of such evaluations to other members of the plant staff;

2. Engineering evaluation of plant conditions required for maintenance and testing; 
3. Engineering evaluation of the adequacy of utility policy for maintenance, testing, equipment procurement, etc.;

4. Engineering evaluation of continuing adequacy of plant operations quality assurance; and

5. Engineering evaluation of adequacy of plant emergency and operating procedures.

There are potentially valuable contributions that this new requirement for a shift technical advisor will have over the long term on overall plant management. It is likely that the most readily available and qualified people to be used to meet this requirement will come from the normal engineering departments of the utilities. It is also possible that the shift assignments of engineers to the operational safety and technical advisor duties will be of a rotational nature. This will serve to bridge the gap between the operations departments and the engineering departments that apparently exists in some utility organizations.

Over the long term, more definitive qualification and training criteria should be developed for shift technical advisors in conjunction with anticipated changes in training and qualifications requirements for reactor operators, senior operators, auxiliary operators, maintenance personnel, and plant managers. Consideration should also be given to the need or value of NRC licensing of shift technical advisors.

\section{POSITION}

Each licensee shall provide an on-shift technical advisor to the shift supervisor. The shift technical advisor may serve more than one unit at a multi-unit site if qualified to perform the advisor function for the various units.

The shift technical advisor shall have a bachelor's degree or equivalent in a scientific or engineering discipline and have received specific training in the response and analysis of the plant for transients and accidents. The shift technical advisor shall also receive training in plant design and layout, including the capabilities of instrumentation and controls in the control room. The licensee shall assign normal duties to the shift technical advisors that pertain to the engineering aspects of assuring safe operations of the plant, including the review and evaluation of operating experience. 
NRR Lessons Learned Task Force

Short-Term Recommendations

TITLE: Shift and Relief Turnover Procedures (Section 2.2.1.c)

\section{INTRODUCTION}

Regulatory Guide 1.33, "Quality Assurance Program Requirements (Operations)," states that each facility should have, among other procedures, a specific procedure that addresses "Shift and Relief Turnover." No guidance, however, is provided to the licensee for the content of such a procedure.

No licensing requirement has been established that identifies a formal checklist as a positive means of accomplishing a transfer of knowledge on system alignment and availability during shift turnover. As a result, the staff cannot assure that conditions do not generally exist in the industry in which shift turnovers can occur without notice that vital safety systems are incorrectly aligned, as apparently was the case with the auxiliary feedwater system at TMI- 2 .

The purpose of this recommendation is to require a shift turnover checklist that is to be completed and signed by the oncoming and offgoing individuals responsible for the command of operations in the control room. Supplemental lists would be used for other members of the operating organization.

\section{DISCUSSION}

Procedures that address shift and relief turnover exist at all facilities; however, the level of detail varies widely. Few procedures require checklists to be completed as an aid to an operator's understanding of plant conditions at the time of shift change. Over the years, as the capabilities of plant computers and data loggers have increased, operator data retrieval has diminished or been eliminated. Thus, instead of requirements to complete a console checklist when relieving a shift, statements such as the following appear in operating procedures:

"Prior to relieving the control room operator on duty the oncoming control room operator should visually observe the main control board and auxiliary system control boards."

There are several features that improved procedures should include, namely:

1. A requirement that the shift supervisor review the general status of the control board and receive confirmation from the control room operators of the proper configuration of controls and systems.

2. An identification of vital safety parameters and equipment deserving particular attention by the control room operators during shift turnover activities.

3. A requirement that the control room operators consciously confirm and attest the performance of detailed control board surveillance steps. 
In the routine of normal plant operations, visual observation of the control board at shift turnover can become perfunctory where only the most obvious mistake would be noticed. If the transfer of information between shifts is verbal then, as apparently happened at TMI-2, the first shift turnover that fails to notice the unavailability of a vital system makes that information unavailable to all subsequent shifts.

There are basically two ways of accomplishing the goal of ensuring that the oncoming shift is aware of critical plant status information and system availability. The first is by electronic means and the second is by manual means.

Plant computers could be programmed to provide the values of all critical parameters and the position, operability, and availability of all safety-related valves, pumps, and systems. The NRC could require that a computer surveillance be performed at each shift turnover and signed by the oncoming control room operator and shift supervisor. This alternative would be costly and take some time to implement, but it has the advantage of being able to check the status of some equipment not displayed in the control room.

The second alternative is to require that a checklist be completed at each shift turnover and signed by the control room operators and shift supervisor on each shift. Such a checklist would be inexpensive, could be implemented quickly, and would give reasonable assurance that the oncoming shift possesses the necessary knowledge of critical plant status information and system availability. Because it is manually accomplished, such a checklist would be limited in scope from an equipment access standpoint. Because a checklist can be easily and quickly implemented, and because it serves to counteract some of the negative effects of routine, automatic operation of plants under normal conditions, the use of such a checklist is recommended for short-term action. The use of plant computers to aid and extend the scope of review of equipment for such activities is not discouraged by the Task Force, as long as the operations personnel are required to complete and attest to a review of the computer status summary.

\section{POSITION}

The licensees shall review and revise as necessary the plant procedure for shift and relief turnover to assure the following:

1. A checklist shall be provided for the oncoming and offgoing control room operators and the oncoming shift supervisor to complete and sign. The following items, as a minimum, shall be included in the checklist:

a. Assurance that critical plant parameters are within allowable limits (parameters and allowable limits shall be listed on the checklist).

b. Assurance of the availability and proper alignment of all systems essential to the prevention and mitigation of operational transients and accidents by a check of the control console 
(what to check and criteria for acceptable status shall be included on the checklist);

c. Identification of systems and components that are in a degraded mode of operation permitted by the Technical Specifications. For such systems and components, the length of time in the degraded mode shall be compared with the Technical Specifications action statement (this shall be recorded as a separate entry on the checklist).

2. Checklists or logs shall be provided for completion by the offgoing and oncoming auxiliary operators and technicians. Such checklists or logs shall include any equipment under maintenance of test that by themselves could degrade a system critical to the prevention and mitigation of operational transients and accidents or initiate an operational transients (what to check and criteria for acceptable status shall be included on the checklist); and

3. A system shall be established to evaluate the effectiveness of the shift and relief turnover procedure (for example, periodic independent verification of system alignments). 
NRR Lessons Learned Task Force

Short-Term Recommendations

TITLE: Control Room Access (Section 2.2.2.a)

\section{INTRODUCTION}

Paragraph (k) of Section 50.43, "Conditions of Licenses," of 10 CFR Part 50 requires that an operator or senior operator 1 icensed pursuant to $10 \mathrm{CFR}$ Part 55, "Operators' Licenses," be present at the controls at all times during the operation of a facility. Regulatory Guide 1.114, "Guidance on Being Operator at the Controls of a Nuclear Plant," describes a method of complying with the regulations that requires an operator to be present at the controls of a nuclear power plant. Regulatory Guide 1.114 states that, in order for the operators to carry out their responsibilities in a timely fashion, attention must be given to the condition of the plant at all times. It further states, as a position, that "... The operator at the controls of a nuclear power plant should have an unobstructed view of and access to the operational control panels, including instrumentation displays and alarms, in order to be able to initiate prompt corrective action, when necessary, on receipt of any indication (instrument movement or alarm) of a changing condition..."

In the course of the accident at TMI-2, there were several instances during which the operator's access to the controls and instrumentation was reported to have been hampered by the accumulation of people in the control room. A further problem was that the presence of senior plant management in the control room called into question the line of authority for operations.

The purpose of this recommendation is to limit the access of personnel to the control room and to establish a clear line of authority for coping with operational transients and accidents.

\section{DISCUSSION}

When an operational transient or accident occurs at a nuclear power plant, the immediate impact is felt by the operators assigned to the control room. Shortly after the event begins, it is typical for other shift personnel to report to the control room for assignment. Later, depending on the severity of the event and the time of day, other persons are called in or voluntarily arrive in the control room. Over a period of time, the number of people in the control room can be excessive to the point of hampering the operators' activities. The problem is compounded if the followup actions stretch over many hours or days, as was the case at TMI-2. There were several times in which the control room had to be forcefully cleared to allow the operators to carry out their assigned responsibilities.

A concurrent problem was that senior plant managers were included among those gathering in the control room at TMI-2. Questions arose as to who was responsible for directing the activities. Only a licensed senior operator may direct the licensed activities of licensed operators. Hence, the shift supervisor is in charge unless relieved by a senior licensed management representative or another shift supervisor. The authority problem can be compounded if the 
senior member of management present in the control room is not 1 icensed. In that case, although he has responsibilities for overall safe plant operations, he does not have the legal authority to direct the licensed activities of the operators, nor does he have the proven knowledge of systems operation that is prerequisite to holding a license.

The recommended short-term solution is to address the control room access and the authority problems through administrative controls. The shift supervisor should be given clear authority to restrict control room access to those individuals responsible for the direct operation of the plant and to technical advisors called in to support that operation in accordanc with a preconceived and well-articulated management plan. The plan must acknowledge that any member of plant management who assumes responsibility from the shift supervisor must possess a current senior operator's license of that unit.

\section{POSITION}

The licensee shall make provisions for limiting access to the control room to those individuals responsible for the direct operation of the nuclear power plant (e.g., operations supervisor, shift supervisor, and control room operators), to technical advisors who may be requested or required to support the operation, and to predesignated NRC personnel. Provisions shall include the following:

1. Develop and implement an administrative procedure that establishes the authority and responsibility of the person in charge of the control room to limit access.

2. Develop and implement procedures that establish a clear line of authority and responsibility in the control room in the event of an emergency. The line of succession for the person in charge of the control room shall be established and limited to persons possessing a current senior reactor operator's license. The plan shall clearly define the lines of communication and authority for plant management personnel not in direct command of operations, including those who report to stations outside of the control room. 
NRR Lessons Learned Task Force

Short-Term Recommendations

TITLE: Onsite Technical Support Center (Section 2.2.2.b)

\section{INTRODUCTION}

Each applicant for a construction permit is required by 10 CFR 50.34 (a) to include in its PSAR a discussion of preliminary plans for coping with emergencies. Each applicant for an operating license is required by paragraph 50.34 (b) to include plans for coping with emergencies in its FSAR. Appendix $E$ to 10 CFR Part 50 establishes minimum requirements for emergency plans. Regulatory Guide 1.101 provides more complete guidance to be used in developing the emergency plans required in FSARs for nuclear power plants. These plans are described in the PSAR and are submitted as a part of the FSAR. They do not consistently cover the role of technical and management personnel during an emergency. Similarly, there are no detailed regulatory requirements concerning the need for technical information on plant status and operation outside of the control room during off-normal events. The capability to transmit and record vital plant data in real-time is also not a current requirement, nor is it required that as-built plant drawings and updated records be available to support emergency activities.

The purpose of this recommendation is to establish a center outside of the control room that acts in support of the command and control function and to improve plant status and diagnostic information at this location for use by technical and management personnel in support of reactor command and control functions.

\section{DISCUSSION}

The recommendations given above for the role of the shift supervisor, the addition of a shift technical advisor, and the limitation of control room access are to be complemented by this recommendation to require the establishment of an onsite technical support center. The activities of plant engineering and management personnel are an important part of the overall station response to an accident and must be properly defined and logistically supported. These people provide the in-depth technical support of control room activities and typically are responsible for the implementation of emergency procedures.

During the first 2 days following the accident at TMI-2, it was difficult for senior government officials to establish contact with senior plant management. It is anticipated that the onsite technical support center will serve as the focal point for such communication in the future.

There is also an indication from the events at TMI-2 that implementation of emergency plans by personnel in the control room acted to congest and confuse the reactor operations control activities. The technical support center would provide a place, in close communication with the control room so as to have sufficient knowledge of current and projected plant status, for more orderly implementation of emergency procedures. 
Review of the TMI-2 accident also shows a lack of reliable technical data, information, and records on which to base accident recovery decisions. Knowledgeable nuclear engineers were unable to understand the details of plant conditions or plant design so as to better advise the operators of appropriate actions for accident recovery.

On many occasions subsequent to the March 28 accident, as-built drawings reflecting the actual configuration of critical portions of the plant were either not available or contained erroneous information. This situation contributed to delays in accident recovery.

Over the long term, it will probably be useful to provide plant status monitoring and recording equipment in the onsite technical support center. The Task Force recommends that requirements in this regard be developed in conjunction with requirements concerning the kind and form of information to be transmitted to the NRC.

\section{POSITION}

Each operating nuclear power plant shall maintain an onsite technical support center separate from and in close proximity to the control room that has the capability to display and transmit plant status to those individuals who are knowledgeable of and responsible for engineering and management support of reactor operations in the event of an accident. The center shall be habitable to the same degree as the control room for postulated accident conditions. The licensee shall revise his emergency plans as necessary to incorporate the role and location of the technical support center.

A complete set of as-built drawings and other records, as described in ANSI N45.2.9-1974, shall be properly stored and filed at the site and accessible to the technical support center under emergency conditions. These documents shall include, but not be limited to, general arrangement drawings, P\&IDs, piping system isometrics, electrical schematics, and photographs of components installed without layout specifications (e.g., field-run piping and instrument tubing). 
NRR Lessons Learned Task Force

Short-Term Recommendations

TITLE: Onsite Operational Support Center (Section 2.2.2.c)

\section{INTRODUCTION}

Each applicant for a construction permit is required by 10 CFR 50.34(a) to include in its preliminary safety analysis report a discussion of preliminary plans for coping with emergencies. Each applicant for an operating license is required by paragraph 50.34(b) to include plans for coping with emergencies in its final safety analysis report. Appendix $E$ to 10 CFR Part 50 establishes minimum requirements for emergency plans. Regulatory Guide 1.101 provides more complete guidance to be used in developing the emergency plans required in FSARs for nuclear power plants. These plans do not consistently cover the role and logistical support for operations support personnel during an emergency.

The purpose of this recommendation is to establish a primary operational support area, to be designated as the onsite operational support center, for shift personnel to be in direct communication with the control room and other operations managers for assignment to duties in support of emergency operations.

\section{DISCUSSION}

During the TMI-2 accident, operational support personnel (e.g., auxiliary operators not assigned to control room, health physics personnel, and technicians) reported to the control room. This contributed to the congestion and confusion in the control room. Although these personnel are required for operations outside of the control room and perhaps a few in the control room, there is a need to restrict their access to only those specifically requested by the shift supervisor to be present in the control room. Thus, there is a need to establish an area in which shift personnel report for further instructions from the operations staff.

\section{POSITION}

An area to be designated as the onsite operational support center shall be established. It shall be separate from the control room and shall be the place to which the operations support personnel will report in an emergency situation. Communications with the control room shall be provided. The emergency plan shall be revised to reflect the existence of the center and to establish the methods and lines of communication and management. 
NRR Lessons Learned Task Force

Short-Term Recommendations

TITLE: Revised Limiting Conditions for Operation of Nuclear Power Plants Based Upon Safety System Availability (Section 2.2.3)

\section{INTRODUCTION}

Section 50.36, "Technical Specifications," of 10 CFR Part 50, "Licensing of Production and Utilization Facilities," requires inclusion of "limiting conditions for operation" in an operating license for a production or utilization facility. "Limiting conditions for operation" are defined as the lowest functional capability or performance levels of equipment required for safe operation of the facility. Violations of technical specifications and descriptions of corrective actions and measures to prevent recurrence are required to be reported to the Nuclear Regulatory Commission. Regulatory Guide 1.16, "Reporting of Operating Information - Appendix A Technical Specifications," provides guidance to licensees in evaluating and reporting violations of limiting conditions for operation.

Violation of a limiting condition for operation can result from several causes including design error, component failure, system miscalibration, improper maintenance, or operator error. Nuclear power plant operating experience shows considerable variability among the error sources. According to the Commission's statistics, human error accounted for 18 percent of all reportable incidents in 1978 (not all of which were violations of limiting conditions for operation), with specific licensed operator error accounting for one-third of that percentage.

Human error, in the form of improper maintenance, calibration, or test of a safety system, can result in the loss of safety system operability. By operability of a safety system, we mean the capability of a system to perform its intended safety function, including allowances for single failures. When human error results in the loss of safety system operability (i.e., violation of a limiting condition for operation), it is common practice for licensees to correct the specific human error, return the safety system to an operable status, and report the occurrence to the Commission. It has been unusual in the past for a plant to be shut down or severely penalized for such an occurrence. The loss of safety function (emergency feedwater) at TMI-2, caused by two closed feedwater admission valves, is an example of a type of violation of limiting condition for operation caused by human error. In this case, it was not a matter of the loss of a single train or channel in a redundant system, but rather a total loss of an essential safety function.

\section{DISCUSSION}

Safety systems of a nuclear power plant are required to be operable as a limiting condition of plant operation. By implication, auxiliary supporting systems essential to continued operation of safety systems are also required to be operational. 
In general terms, the safety systems of a nuclear power plant consist of the following:

Reactor Trip Systems

Engineered Safety Features Systems

Systems Required for Safe Shutdown

The Reactor Trip System, which is part of the reactor protection system, includes those power sources, sensors, initiation circuits, logic matrices, bypasses, interlocks, racks, panels, control boards, and actuation and actuated devices that are used to initiate reactor shutdown.

The remaining portion of the protection system is the engineered safety features actuation system. Typical engineered safety features (ESF) systems include the following:

Containment and Reactor Vessel Isolation Systems

Emergency Core Cooling Systems (ECCS)

Containment Heat Removal and Depressurization Systems

Pressurized Water Reactor Auxiliary Feedwater Systems

Boiling Water Reactor Standby Gas Treatment Systems

Containment Air Purification and Cleanup Systems

Containment Combustible Gas Control Systems

Auxiliary supporting systems essential to operation of ESF systems typically include:

Emergency Electric Power Systems

Diesel Generator Fuel Storage and Transfer Systems

Instrument Air Systems

Heating, Ventilating, and Air Conditioning (HVAC) Systems for ESF Areas

Essential Service Water Systems

Examples of systems required for achieving and maintaining a safe shutdown include:

Auxiliary Feedwater System (PWRs)

Residual Heat Removal System (PWRs and BWRs)

Boric Acid Transfer System (PWRs)

High-Pressure Injection and Pressure Relief Systems (BWRs)

Finally, in either a hot shutdown or cold shutdown condition, it is necessary that reactivity control systems maintain a subcritical condition of the core.

To achieve high operational reliability for performance of safety systems, the NRC evaluates the system designs for conformance to safety criteria (such as diversity, redundancy, separation, and environmental qualification), mandates technical specifications (which influence test, maintenance, and operability of the system), licenses operators to assure the proper manual control and verification of automatic operation of the systems, and conducts field inspections and evaluations at operating plants to ensure conformance to the technical 
specifications. Although these actions represent many levels of regulation and review, human error, such as procedural error, can result in the loss of a safety function.

The closed auxiliary feedwater isolation valves at TMI-2 are an example of losses of safety function that can be prevented through quality assurance in the execution of operating, testing, and maintenance procedures and the rigid application of technical specifications for operation. Of the approximately 3,000 Licensee Event Reports in 1978, it is estimated that about 1 percent involved the loss of safety function through human (operational) error.

Human error can result in the undetected as well as detected loss of safety function. In some cases, human error results in common-mode failure of a safety function, such as the loss of auxiliary feedwater at TMI-2. Human error can be minimized through operator training, discipline, and a rigid quality assurance program in the operation, test, maintenance and repair of the plant. The goal should be to eliminate the occurrence of loss of any safety function due to human error.

In evaluating regulatory mechanisms for improving operational reliability and eliminating human errors of the magnitude that yield a complete loss of safety function, the Task Force considered two basic alternatives: (a) more detailed review and inspection of procedures and licensee operations management, and (b) clearer definition of the kinds of operational errors that are inconsistent with continued assurance of the licensee's qualifications to operate the plant.

Recognizing that operations quality assurance is, under current Commission regulations, the responsibility of the licensee, and recognizing that the past trend of increasingly detailed staff reviews has not been effective in eliminating these severe types of operational errors, the Task Force decided upon the second approach.

In developing that approach, we considered alternatives to the following steps in its implementation:

1. Definition of a clear threshold for violation,

2. Assessment of the violation and selection of corrective action by the licensee, and

3. NRC review of the corrective action chosen by the licensee.

In defining a threshold for violation, we compared the results of human errors to the results of design errors. Design errors that lead to loss of a safety function are generally not correctable without plant shutdown and redesign under current limiting conditions for operations. Thus, continued operation is not allowed for this source of loss of safety function. Human errors that result in a loss of safety function are usually amenable to prompt and specific correction. They must be reported to NRC, but the current methods of regulation do not clearly mandate broad and definitive corrective action by the licensee. In order to provide a clearly identifiable threshold for violation and in 
order to be consistent with the current treatment of limiting conditions for operation insofar as design errors are concerned, we have chosen the complete loss of safety function as the trigger for initiating thoroughgoing review of operational reliability.

The Task Force believes there is a need to significantly increase licensees' awareness of the need to generally improve operations reliability. The assessment of fines is one way to do that. The disadvantage is that the process takes time, hence delaying a clear signal to a licensee that the kind of human error that leads to loss of safety function is intolerable. Furthermore, the use of fines for human errors of this severity tends to shift the burden of responsibility for their detection and prevention to the NRC, rather than to the licensee's corporate management. Thus, the Task Force prefers that the penalty in this instance should be in the nature of plant shutdown. We believe the threshold for violation has been set high enough to justify that level of penalty.

The Task Force recommends that this requirement be promptly promulgated through immediately effective rule change. In the course of this rulemaking, the Commission should give consideration to shortening the required time for notice of public meetings (presently two weeks) for this particular type of public meeting.

\section{POSITION}

All NRC nuclear power plant licensees shall provide information to define a limiting operational condition based on a threshold of complete loss of safety function. Identification of a human or operational error that prevents or could prevent the accomplishment of a safety function required by NRC regulations and analyzed in the license application shall require placement of the plant in a hot shutdown condition within 8 hours and in a cold shutdown condition within 24 hours.

The loss of operability of a safety function shall include consideration of the necessary instrumentation, controls, emergency electrical power sources, cooling or seal water, lubrication, operating procedures, maintenance procedures, test procedures and operator interface with the system, which must also be capable of performing their auxiliary or supporting functions. The limiting conditions for operation shall define the minimum safety functions for modes 1 , $2,3,4$, and 5 of operation.

The limiting conditions of operation shall require the following:

1. If the plant is critical, restore the safety function (if possible) and $p l a c e$ the plant in a hot shutdown condition within 8 hours.

2. Within 24 hours, bring the plant to cold shutdown.

3. Determine the cause of the loss of operability of the safety function. Organizational accountability for the loss of operability of the safety system shall be established. 
4. Determine corrective actions and measures to prevent recurrence of the specific loss of operability for the particular safety function and generally for any safety function.

5. Report the event within 24 hours by telephone and confirm by telegraph, mailgram, or facsimile transmission to the Director of the Regional office, or his designee.

6. Prepare and deliver a Special Report to the NRC's Director of Nuclear Reactor Regulation and to the Director of the appropriate regional office of the Office of Inspection and Enforcement. The report shall contain the results of steps 3 and 4 , above, along with a basis for allowing the plant to return to power operation. The senior corporate executive of the licensee responsible and accountable for safe plant operation shall deliver and discuss the contents of the report in a public meeting with the Office of Nuclear Reactor Regulation and the Office of Inspection and Enforcement at a location to be chosen by the Director of Nuclear Reactor Regulation.

7. A finding of adequacy of the licensee's Special Report by the Director of Nuclear Reactor Regulation will be required before the licensee returns the plant to power. 


\section{APPENDIX B}

NRR LESSONS LEARNED TASK FORCE

IMPLEMENTATION OF SHORT-TERM RECOMMENDATIONS 
NRR Lessons Learned Task Force

Implementation of Short-Term Recommendations

In conjunction with development of its short-term recommendations, the Lessons Learned Task Force has addressed the schedule for implementation of the recommendations on the various categories of plants. The schedule, given in detail in Table B-1, recognizes two sets of plants. The first set is comprised of post-CP plants and plants in $C P$ review. They are required to commit to conform to the short-term recommendations. The second set is comprised of operating plants and plants in $O L$ review and makes provision for implementation of the short-term requirements in two phases.

The intent of the two-phase implementation is to provide maximum timely improvements in safety consistent with practical limitations on the ability of licensees and applicants to design, procure, and install equipment, or to develop and implement administrative changes. The Task Force has categorized the short-term recommendations into those that are essentially procedural in nature (Category $A$ ) and can therefore be implemented expeditiously ( $p r i o r$ to January 1,1980 ) and those that involve design changes and/or hardware procurement and installation (Category $B$ ) and will require a longer time period (prior to January 1, 1981). While allowing the longer time period for Category $B$ items, the Task Force believes that many of these can be and should be accomplished within a shorter time frame. To this end, the Task Force also recommends that meetings be scheduled with all operating plant licensees and applicants for OLs to establish plant-specific schedules for the Category B items. At these meetings, the need for providing scheduled relief in specific instances for good cause will also be considered. Table B-1 identifies the specific category of each of the short-term recommendations.

Post-CP Plants and CP Applicants

For all plants in $C P$ review and all plants under construction for which an $O L$ application has not yet been tendered, the applicant/CP holder shall provide a commitment to comply with the recommendations of this report within 30 days of receipt of a letter from the Office of Nuclear Reactor Regulation specifying the particular licensing requirements that apply to each particular plant design. All requirements of each position shall be incorporated into the plant design as appropriate and described in the Final Safety Analysis Report when an application for an operating license is tendered.

\section{Operating Plants and OL Applicants}

For operating plants, implementation of the recommendations shall be in two phases, as specified in Table B-1. Category $A$ items shall be implemented prior to January 1,1980 , and Category B items prior to January 1, 1981, with the exception of the safety and relief valve qualification testing (July 1, 1981). For plants with tendered OL applications, Category $A$ items shall be implemented prior to receipt of an $0 L$. Specific schedules for the Category $B$ items will be developed in meetings with licensees and applicants to be conducted within 30 days. 
TABLE B-1. IMPLEMENTATION OF SHORT-TERM RECOMMENDATIONS FOR OPERATING PLANTS AND PLANTS IN OL REVIEW

\begin{tabular}{|c|c|c|c|}
\hline \multirow[b]{2}{*}{$\begin{array}{l}\text { Sect. } \\
\text { No. }\end{array}$} & \multicolumn{2}{|c|}{ Position } & \multirow[b]{2}{*}{$\begin{array}{l}\text { Implementation } \\
\text { Category } \\
\end{array}$} \\
\hline & $\begin{array}{l}\text { Abbreviated } \\
\text { Title }\end{array}$ & $\begin{array}{l}\text { Position } \\
\text { Description }\end{array}$ & \\
\hline 2.1 .1 & $\begin{array}{l}\text { Emergency Power Supply } \\
\text { Requirement }\end{array}$ & $\begin{array}{l}\text { Complete implementa- } \\
\text { tion. }\end{array}$ & A \\
\hline 2.1 .2 & $\begin{array}{l}\text { Relief and Safety Valve } \\
\text { Testing }\end{array}$ & $\begin{array}{l}\text { Submit program descrip- } \\
\text { tion and schedule. }\end{array}$ & A \\
\hline & & Complete test program. & By July $1981^{b}$ \\
\hline 2.1.3.a & $\begin{array}{l}\text { Direct Indication of } \\
\text { Valve Position }\end{array}$ & Complete implementation. & A \\
\hline 2.1.3.b & $\begin{array}{l}\text { Instrumentation for } \\
\text { Inadequate Core Cooling }\end{array}$ & $\begin{array}{l}\text { Develop procedures and } \\
\text { describe existing instr. }\end{array}$ & A \\
\hline & & $\begin{array}{l}\text { New instr. design, sub- } \\
\text { cooling meter installatio } \\
\text { and implementation schedu }\end{array}$ & te. \\
\hline & & $\begin{array}{l}\text { Complete new instr. } \\
\text { installation. }\end{array}$ & B \\
\hline 2.1 .4 & $\begin{array}{l}\text { Diverse Containment } \\
\text { Isolation }\end{array}$ & Complete implementation. & $A$ \\
\hline $2.1 .5 . a$ & $\begin{array}{l}\text { Dedicated } \mathrm{H}_{2} \text { Control } \\
\text { Penetrations }\end{array}$ & $\begin{array}{l}\text { Description and imple- } \\
\text { mentation schedule. }\end{array}$ & A \\
\hline & & Complete installation. & B \\
\hline
\end{tabular}

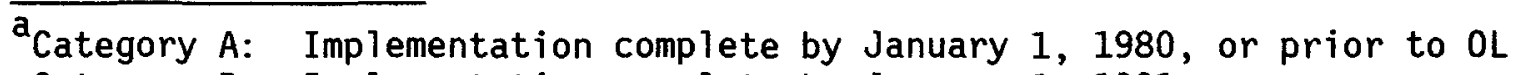
Category B: Implementation complete by January 1, 1981.

${ }^{b}$ Relief and safety valve testing shall be satisfactorily completed for all plants prior to receiving an operating license after July 1, 1982.
} 
TABLE B-1 (Continued)

\begin{tabular}{|c|c|c|c|}
\hline \multirow[b]{2}{*}{$\begin{array}{l}\text { Sect. } \\
\text { No. } \\
\end{array}$} & \multicolumn{2}{|c|}{ Position } & \multirow[b]{2}{*}{$\begin{array}{c}\text { Implementatjon } \\
\text { Category }\end{array}$} \\
\hline & $\begin{array}{c}\text { Abbreviated } \\
\text { Title } \\
\end{array}$ & $\begin{array}{l}\text { Position } \\
\text { Description }\end{array}$ & \\
\hline \multirow[t]{3}{*}{$2.1 .5 . b$} & $\begin{array}{l}\text { Rulemaking to Require } \\
\text { Inerting BWR Containments }\end{array}$ & $\begin{array}{l}\text { Inert Vermont Yankee } \\
\text { and Hatch } 2 .\end{array}$ & * \\
\hline & & $\begin{array}{l}\text { Design and equipment } \\
\text { to inert new Mark I } \\
\text { and II containments. }\end{array}$ & $*$ \\
\hline & & $\begin{array}{l}\text { Inert new Mark I and } \\
\text { II containments. }\end{array}$ & * \\
\hline \multirow[t]{2}{*}{$2.1 .5 . \mathrm{C}$} & $\begin{array}{l}\text { Combustible Gas Control } \\
\text { Recombiner }\end{array}$ & $\begin{array}{l}\text { Rulemaking to require } \\
\text { capability of installing } \\
\text { recombiners. }\end{array}$ & * \\
\hline & & $\begin{array}{l}\text { Review procedures and } \\
\text { bases for recombiner use. }\end{array}$ & B \\
\hline \multirow[t]{2}{*}{$2.1 .6 . \mathrm{a}$} & $\begin{array}{l}\text { Systems Integrity for } \\
\text { High Radioactivity }\end{array}$ & $\begin{array}{l}\text { Immediate leak } \\
\text { reduction program. }\end{array}$ & A \\
\hline & & $\begin{array}{l}\text { Preventive maintenance } \\
\text { program. }\end{array}$ & $A$ \\
\hline \multirow[t]{2}{*}{$2.1 .6 . b$} & Plant Shielding Review & $\begin{array}{l}\text { Complete the design } \\
\text { review. }\end{array}$ & $A$ \\
\hline & & $\begin{array}{l}\text { Implement plant } \\
\text { modifications. }\end{array}$ & B \\
\hline $\begin{array}{l}{ }^{\mathrm{a}} \text { Category } \\
\text { Category }\end{array}$ & $\begin{array}{l}\text { A: Implementation complete } \\
\text { B: Implementation complete }\end{array}$ & $\begin{array}{l}\text { by January } 1,1980 \text {, or prior } \\
\text { by January } 1,1981 \text {. }\end{array}$ & or to $\mathrm{OL}$ \\
\hline
\end{tabular}


TABLE B-1 (Continued)

\begin{tabular}{|c|c|c|c|}
\hline \multirow[b]{2}{*}{$\begin{array}{l}\text { Sect. } \\
\text { No. }\end{array}$} & \multicolumn{2}{|c|}{ Position } & \multirow[b]{2}{*}{$\begin{array}{l}\text { Implementatjion } \\
\text { Category }\end{array}$} \\
\hline & $\begin{array}{c}\text { Abbreviated } \\
\text { Title } \\
\end{array}$ & $\begin{array}{c}\text { Position } \\
\text { Description }\end{array}$ & \\
\hline \multirow[t]{2}{*}{ 2.1.7.a } & \multirow[t]{2}{*}{$\begin{array}{l}\text { Auto Initiation of } \\
\text { Auxiliary Feed }\end{array}$} & $\begin{array}{l}\text { Complete implementation } \\
\text { of control grade. }\end{array}$ & A \\
\hline & & $\begin{array}{l}\text { Complete implementation } \\
\text { for safety grade. }\end{array}$ & B \\
\hline $2.1 .7 . b$ & $\begin{array}{l}\text { Auxiliary Feed Flow } \\
\text { Indication }\end{array}$ & Complete implementation. & A \\
\hline \multirow[t]{4}{*}{$2.1 .8 . a$} & \multirow[t]{4}{*}{ Post-Accident Samp1ing } & Design review complete. & A \\
\hline & & $\begin{array}{l}\text { Preparation of } \\
\text { revised procedures. }\end{array}$ & A \\
\hline & & $\begin{array}{l}\text { Implement plant } \\
\text { modifications. }\end{array}$ & B \\
\hline & & $\begin{array}{l}\text { Description of proposed } \\
\text { modification. }\end{array}$ & A \\
\hline 2.1.8.b & $\begin{array}{l}\text { High Range Effluent } \\
\text { Monitor }\end{array}$ & Installation complete. & B \\
\hline $2.1 .8 . \mathrm{c}$ & $\begin{array}{l}\text { Improved Iodine } \\
\text { Instrumentation }\end{array}$ & Complete implementation. & A \\
\hline 2.1 .9 & $\begin{array}{l}\text { Transient \& Accident } \\
\text { Analysis }\end{array}$ & $\begin{array}{l}\text { Complete analyses, } \\
\text { procedures \& training. }\end{array}$ & $* *$ \\
\hline \multicolumn{4}{|c|}{ 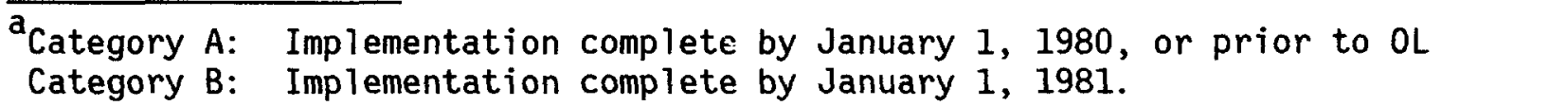 } \\
\hline
\end{tabular}


TABLE B-1 (Continued)

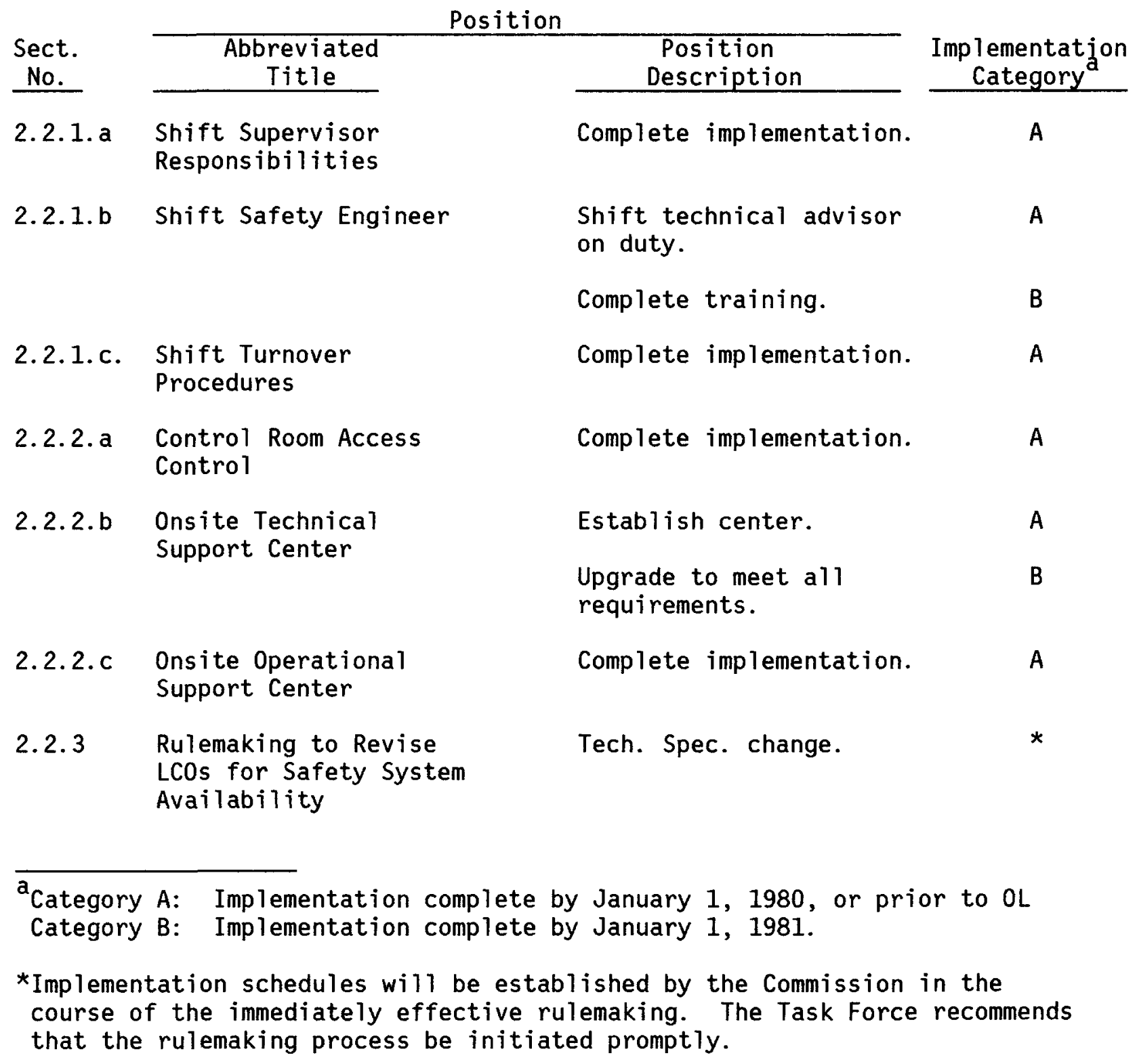




\section{Task Description}

1. Small Break LOCA analys is and preparation of emergency procedure guidelines

2. Implementation of small break LOCA emergency procedures and retraining of operators

3. Analysis of inadequate core cooling and preparation of emergency procedure guidelines

4. Implementation of emergency procedures and retraining related to inadequate core cooling

5. Analysis of accidents and transients and preparation of emergency procedure guidelines

6. Implementation of emergency procedures and retraining related to accidents and transients

7. Analysis of LOFT small break tests
Completion Date

JuTy-September 1979*

December 31, 1979

October 1979

January 1980

Early 1980

3 months after guidelines established

Pretest

(mid-September 1979)

*Range covers completion dates for the four NSSS vendors. 
NRC FORM 335

(777)
U.S. NUCLEAR REGULATORY COMMISSION

BIBLIOGRAPHIC DATA SHEET

4 TITLE AND SUBTITLE (Add Volume No, if appropriate)

TMI-2 Lessons Learned Task Force: Status Report and Short-Term Recommendations

7 AUTHOR(S)

9 PERFORMING ORGANIZATION NAME AND MAILING ADDRESS (Include $Z_{1 p}$ Code)

U.S. Nuclear Regulatory Commission

Office of Nuclear Reactor Regulation

Washington, D.C. 20555

12 SPONSORING ORGANIZATION NAMF AND MAILING ADDRESS (Include $Z i p$ Code)

Same as 9. above.

PERIOD COVERED (/nclusive dates)

13 TYPE OF REPORT

Technical Report

15 SUPPLEMENTARY NOTES

14 (Leave blank)

16 ABSTRACT (200 wards or less)

Review of the Three Mile Island accident by the TMI-2 Lessons Learned Task Force has disclosed a number of actions in the areas of design and analysis and plant operations that the Task Force recommends be implemented in the short term to provide immediate, substantial additional protection for the public health and safety. All nuclear power plants in operation or in various stages of licensing action are affected to varying degrees by the specific recommendations. The Task Force is continuing work in the areas of General Safety Criteria, System Design Requirements, Nuclear Power Plant Operations, and Nuclear Power Plant Licensing.

\begin{tabular}{|c|c|}
\hline $\begin{array}{c}19 \text { SECURITY CLASS (This report) } \\
\text { Unclassified }\end{array}$ & 21 NO OF PAGES \\
\hline $\begin{array}{c}20 \text { SECURITY flASS (This page) } \\
\text { UnClaSS ified }\end{array}$ & $\begin{array}{c}22 \text { PRICE } \\
\$\end{array}$ \\
\hline
\end{tabular}

